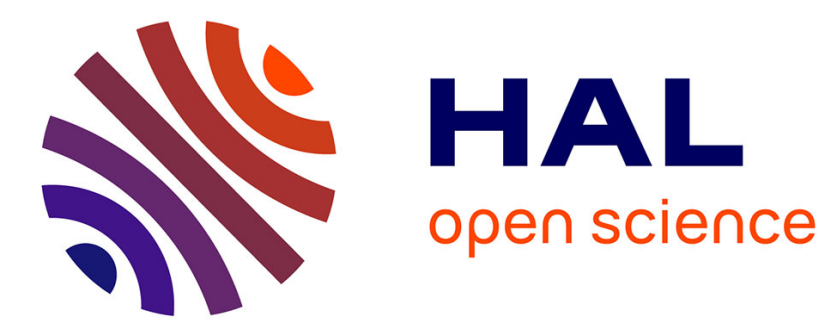

\title{
Les ensembles ornementaux illimités d'Angkor
}

François Bizot

\section{To cite this version:}

François Bizot. Les ensembles ornementaux illimités d'Angkor. Arts Asiatiques, 1970, 21, pp.109 150. 10.3406/arasi.1970.1022. hal-03584294

\section{HAL Id: hal-03584294 \\ https://hal.science/hal-03584294}

Submitted on 22 Feb 2022

HAL is a multi-disciplinary open access archive for the deposit and dissemination of scientific research documents, whether they are published or not. The documents may come from teaching and research institutions in France or abroad, or from public or private research centers.
L'archive ouverte pluridisciplinaire HAL, est destinée au dépôt et à la diffusion de documents scientifiques de niveau recherche, publiés ou non, émanant des établissements d'enseignement et de recherche français ou étrangers, des laboratoires publics ou privés. 


\section{Les ensembles ornementaux illimités d'Angkor}

François Bizot

\section{Citer ce document / Cite this document :}

Bizot François. Les ensembles ornementaux illimités d'Angkor. In: Arts asiatiques, tome 21, 1970. pp. 109-150;

doi : https://doi.org/10.3406/arasi.1970.1022

https://www.persee.fr/doc/arasi_0004-3958_1970_num_21_1_1022

Fichier pdf généré le 20/04/2018 


\title{
LES ENSEMBLES ORNENENTAUX ILLINITÉS D’ANGKOR
}

par François BIZOT

\author{
"Ile shall find that asialic art is ideal in \\ the mathemalical sense: lilie valure, not in \\ appearance, but in operation."
}

Ananda K. Coomaraswamy 1)

\section{INTROIOLCTJON}

L'ornementation est l'art de disposer des motifs selon l'harmonie d'une structure symétrique (2). L'ordre ainsi déterminé sous-entend le rỵthme (3) et implique la subordination des parties au tout. Les structures obéissent à des lois générales et leurs possibilités ont été exploitées d'une façon analogue à des périodes et par des rultures différentes. Mais les motifs qui sont les éléments suivant lesquels une figure s'exprime, ont été. en raison de leur nature contingente, le receptacle des symboles, des styles et des influences qui ont présidé a leur élaboration.

1) A. K. Coomaraswamy, The transformution of nulure in .1rl. I. The theory "f Art in .1sia, New York 1956, p. 11

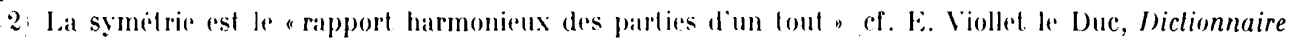
raisonne de l'Archileclure, 1. VIII, Paris, p. 5ll.

3 "Lieursthmie etant partie essentielle de la sỵmetrie ", ibid., p. 5l?. . 
Ce travail traite d'un aspect spécial de l'ornementation de l'ancien Camborge, celui du décor répétant ses motifs dans deux directions et dont la structure à développement indéfini est celle des ensembles dits "illimités".

Le système de réseau à deux dimensions a ceci de particulier qu'il s'adapte. indistinctement à toutes les surfaces sans devoir pour cela s'y limiter. Il suffira de posséder un échantillon du décor pour pouvoir en supposer le reste et le connaitre entièrement. De là, qu'il enrichisse un champ large ou restreint, sa structure est la mème, ses possibilités sont totales, sal nature se conserve intégralement. C'est dans de telles propriétés qu'il faut sans doute rhercher la raison pour laquelle ce décor, ou du moins un décor présentant des possibilités analogues, s'est ru tout particulièrement choisi pour l'ornementation rles tissus. I)'ailleurs, d'une façon fort significative, les figures correspondant à un tel décor, même si elles s'appliquent à de tout autres surfaces, sont souvent désignées en cambodgien par kpāc' kralä sambal' (1) (ornement en réseau pour tissus). En rffet, les étoffes utilisaient au mieux de telles possibilités; elles étaient appelées à constituer de larges surfaces, aussi bien qu'à ètre taillées suivant les formes variées des diverses pièces d'un ensemble. Et ceci recommanda logiquement le choix d'un décor qui unifie cet ensemble ainsi formé au lieu de souligner, en les différenciant, ses diverses parties constitutives.

L'étude des caractéristiques et des possibilités de ces figures, que l'on trouve déjà à Sambor Prei Kuk $(2)$ et que le décor moderne utilise encore, sera limitée à relles des monuments du groupe d'Angkor (Banteay Srei et Banteay Samré inclus). En premiere partie, on trouvera la description des ensembles ornementaux illimités tels qu'ils apparaissent 1) dans le décor des bas-reliefs, 2) dans celui de l'architecture. Ensuite, en seconde partie, il sera traité de la nature ornementale de ces ensembles, ce qui pourra servir, à cet égard, comme une contribution à l'étude de l'ornementation en général.

(1) I.es expressions of les termes cambodgiens employés de nos jours, tout particulierement par les artistes de la region de Siemreap ot par quelques spécialistes de Phnom Penh, ont été utilises charque fois qu'ils se sont appliqués à nos figures, mais aussi, charque fois que leur emploi particulier, trop souvent soumis a des variantes individuelles, n'a fait, d'une facon generale, l'objet d'aucune contradiction.

Pour la representation de ces mots cambodgiens on a utilisé la translitteration usite pour les écritures indiennes ou dorigine indienne, completie par des signes diacritiques correspondant aux phonemes propres au cambodgrien cf. Au Chhieng, dans . Volice sur les caractires elrangers de l'Imprimerie nalionale, 2c ed., Paris 19.4x, p. 307-316 . Ce șstime représente en lettres latines les caracteres cambodgriens aux-mêmes, donc l'ortho-

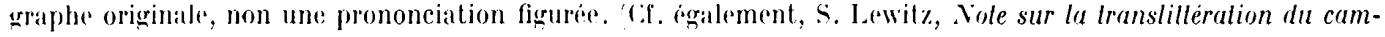
bodyien, BEFEO) 1969, p. 163-169?.

$\because$ Reproduil dans H. Marchal, Le decor el la sculphure hihmers, l'aris 1951, pl. V111/27. 


\section{PREMIERE PARTIE}

\section{J. LE DÉCOR DES BAS-RELIEFS}

Les bas-reliefs d'Angkor Vat et du Bayon donnent de riches exemples (pl. I) de motifs et de figures employés dans l'ornementation des tissus de cette époque. On en trouve aussi bien sur les vestes, les maillots, les gilets, les langoutis, les sampots et les turbans des personnages que sur les rideaux, les tentures, les éventails, les parasols, les étendards et les tapis ainsi que sur certaines pièces de harnachement des diverses montures. Leur régularité d'exécution et la répétition des mèmes motifs suivant des figures semblables ont permis d'en faire le classement. Les dissemblances qu'il est possible de relever entre l'ornementation des tissus des bas-reliefs d'Angkor Vat et celle de ceux du Bayon, ne touchent que quelques détails isolés, comme certaines variantes de motifs ; et malgré quelques ensembles (1) plus particulièrement développés dans l'un ou l'autre monument, il apparaît que, dans ses grandes lignes, le décor reste toujours le mème.

L'étude de ces figures se subdivise logiquement en celles des motifs et des structures.

\section{Les notirs.}

Ils sont peu nombreux et se laissent facilement grouper malgré un cerlain nombre de variantes. Cinq sortes de motifs semblent pouvoir être déterminés : les motifs floraux de face et de profil, les motifs floraux riliés, ainsi que les motifs circulaires et quadrangulaires.

Les molifs floraux de face. Ils sont encore très répandus au liambodge, et tout le monde s'arcorde sur leur nom : il s'agit de la fleur d'une Eibénacée (un Diospyros) que les Khmers appellent phkā cān' (2). Mais ce terme désigne également des motifs parfois différents ayant cependant la particularité de se présenter toujours de face. Sur les bas-reliefs d'Angkor cette fleur est sans doute le motif le plus utilisé. Lees

1, Les figures 5, 6 o 8 de la planche 11 sont particulieres au Bayon; nolons aussi que les vêlements recouverts d'ecailles imbripuees que l'on y trouve, ont ele consideres comme des sortes de colles de mailles ct n'ont pas cete releves.

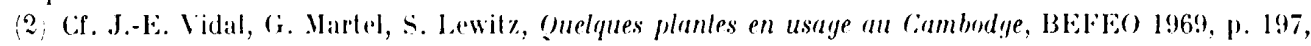
art. 86 . 
pétales, dont le nombre peut varier dans un mème ensemble - trois, quatre, cinq, six, huit - sont figurés le plus souvent par quatre demi-pastilles, gravées finement selon de petits ares de cercle autour d'un anneau central (pl. I, parasols, ete.); ces ares de cercle sont parfois doubles ou triples, mais aussi, ils peuvent être acuminés (pl. III/1, 5), en accent circonflexe, ciliés (pl. Il/9), voire à queues axillaires (pl. I, maillot du personnage central) ; ils peuvent également s'inscrire dans un carré (pl. V/15, 16, 17, 18), dans un cercle (pl. II/8) dans un quadrilobe (pl. II/5), 6), ou encore, par l'adjonction de feuilles, donner lieu a différentes compositions (pl. II/15), $16 ; \mathrm{pl}$. III/9, $10 ; \mathrm{pl} . \mathrm{I} / 7)$.

Les molifs floraux de profil. Ils correspondent à un groupe bien déterminé malgré leur emploi peu usité sur les bas-reliefs. Dans tous les cas, ils sont représentés de profil suivant un nombre généralement impair de pétales longs et acuminés disposés autour d'un ou deux boutons centraux ( $\mathrm{pl}$. I广/3, 6). I) plus, ils sont toujours présentés suivant les souples volutes d'une liane sarmenteuse, le plus souvent légèrement feuillue. (On s'accorde généralement à nommer ces motifs bhñi des (1) (lleur exotique).

Les molifs floraux ciliés. Ils sont dans la plupart des cas simplement constitués d'un anneau central entouré de cils en quart de rond (pl. I, maillot des personnages du registre inférieur), plus ou moins bouclés ( $\mathrm{pl}$. II/21), voire frisés. Leur aspect qui peut varier dans une mème figure va jusqu'à constituer un large disque dessiné par plusieurs spirales concentriques (pl. II/222) (2). Il ne semble pas qu'un nom puisse être retenu pour ces motifs (3), pourtant recopiés sur des tissus modernes.

Les molifs circulaires. Ils se rencontrent le plus souvent sous la forme de petits anneaux (pl. II/25), 26), parfois constitués par deux cercles concentriques (pl. II/2:3), 24). Sous l'aspect d'un anneau simple, ce motif est pour certains d'origine végétale et peut recevoir, entre autre, le nom de phkia mrec (fleur de poivrier); d'autres verront là un élément géométrique.

1) Bhnii designe les "fleurs arrangress dans un but dicoralif ou cultuel ". Il est attesti depuis longtemps dans les inscriptions sous les formes rie ou viuga virux khmer) et bhñi khmer movenj. Quant à des, c'rst la réduction du sanscrit deśa "payss, pays dus Indiens "; "mploye comme qualificatif, il signifie "venir de l"Inde" el, par extension, o importe, eitranger"

En ce qui concerne le decor angkorien, la simplicite d'une part et la rigueur d'exécution d'autre part, permettent parfaitement bien de determiner les motifs à qui ce terme moderne? sapplique. Cipendant, le style d'Angkor devail evoluer pour se compliquer d'un certain nombre de fanlaisies quine terminologie ne peut plus saisir ave precision. Ainsi, les artistes modernes font un large usage de "bhñi des ", mais ces molifs different parfois sensiblement les uns de's antres. D'aillents le Dictionmaire khmer Institut Bouddhique de Phnom Penh, 3" éd., 1962 definit ainsi ce motif : ormement à tiges, feuilles, fleturs el fruits.

2 Il convient de noter une curieruse variante de ce molif, relerée a Angkor Vat sur le maillot d'un persomnage, an sud de la galerie septentrionale des has-reliefs, partie sud : le motif dessine un point d'interrogration couche of cilie, at figure ainsi l'esquisse d'une concue marine.

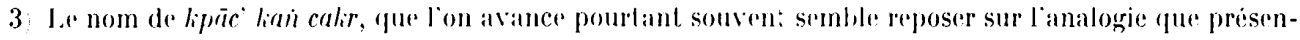
lent les cils du motif avec les rayons du disque calira voir plus foin p. 1.5 note 2. . Mais les bas-reliefs cux-mêmes, ou simplement une home reproduction du motif, dissipent genterilement lia confusion. 
Les molifs quadratiques. Ils sont déterminés par les figures simplement quadrillées et se présentent sous la forme de carrés droits $(\mathrm{pl} . \mathrm{V} / 1,3)$ ou diagonaux $(\mathrm{pl} . \mathrm{V} / 2,4)$; ces carrés s'ornent souvent de divers motifs qui peuvent ètre notamment d'autres carrés (pl. V/7, 8, 9). Exceptionnellement on rencontre des losange's (pl. II/11, 27; pl. V/24).

\section{I.ES STRCCTLRES.}

L'ordre suivant lequel s'organisent les motifs d'une figure détermine un agencement régulier, fondamental pour cette figure. Dans les bas-reliefs d'Angkor, les structures n'ont pas toutes été pareillement exploitées et certains motifs ont servi plus particulièrement à quelques ensembles, alors que d'autres étaient utilisés dans presque tous les cas. Mais d'une façon générale, deux grandes dispositions s'imposent préalablement à tous les ensembles : ceux-ci se présentent soit suivant les axes verticaux et horizontaux, soit suivant des axes diagonaux. Il est difficile de préciser leur différence et dans certains cas l'on pourrait croire que leurs possibilités rigoureusement identiques permettent de faire pivoter l'un pour retrouver lautre. Mais c'est suivant la nature du motif que cette superposition s'affirmera possible ou non. En effet, un motif cruciforme debout se transformera en sautoir, si la figure dont il est solidaire subit une rotation de $45^{0}$. Toutefois, encore que le cas se rencontre (pl. V/16), la grande majorité des ensembles conservent et présentent toujours leurs motifs debout. En camborlgien, ces deux dispositions se nomment kpāc, kralā traì' (ornement en réseau droit) et kpāc' kra!̣a pradis (ornement en réseau de treillis); en effet, le treillis en lattes de bambou, très employé dans le décor moderne, se rencontre presque toujours en diagonale afin d'utiliser la longueur totale des perches plus avantageusement que dans une trame horizontale. Mais, dans le décor ancien, on trouve indifféremment, et à part égale semble-t-il, l'un ct l'autre.

l'une façon générale, la structure d'un décor s'exprime suivant une figure qui peut se composer de plusieurs ensembles, constitués char'un par un nombre indéfini d'éléments (ou motifs) semblables. Les axes d'une figure ou d'un ensemble, qui sont les parallèles aux droites d'un réseau dont les nouds seraient les éléments de cette figure ou de cet ensemble (1), en déterminant la position, qui sera droite ou, inversement, diagonale selon que ses axes seront respectivement verticaux et horizontaux ou, au contraire, diagonaux.

Les structures des figures (2) renentrées sur les bas-reliefs d'Angkor ont permis de déterminer trois atégories : les semis, les ramages :3) at les réseaux.

1 En effet, un ensemble droil, par exemple, peul toujours recevoil des lignes diagonales ; mais, ces lignes se croisant en queleque sorte a linterieur des mailles, leur intersection ne precisera plus les blements de la figure.

2. Les lignes suivant tespuelles les figures sorganisent tendent a delerminer des mailles quadratiques; dans la presque lolalile des cas alles y seront assimilers.

3. Le sens general de ce termo : "molif decoralif fait de rameanx ed de feuilles ", a lavantage de sappliguer beralement an differenles expressions de ces ensembles pour lesplurltes un termt plus precis liane, par exomple, nammit pas converum dans tous las cas. 
Les semis. Ils s'expriment suivant des figures qui présentent leurs motifs régulièrement parsemés sur un champ nu, au rythme d'une structure non figurée. On peut discerner les ensembles disposés de manière à présenter une figure droite ou diagonale, et, pour charune de ces subdivisions, ceux constitués par un seul élément ou par deux éléments alternés. Il est parfois difficile de déterminer si ces figures sont droites ou diagonales et les deux dispositions peuvent se rencontrer dans un même ensemble. Ceci est tout particulièrement remarquable dans le décor des vètements des personnages en mouvement. Parfois des figures sont disposées suivant une structure imprécise (pl. II/7, 15, 16), ou peuvent encore avoir leurs éléments principaux disposés symétriquement, alors que d'autres motifs, plus simples, alternent sans précision avec eux (pl. II/21).

Les ramages. Cie sont des figures très particulières. Ainsi, un décor de phkã cān' disposé suivant un réseau diagonal pourra illustrer tous les autres ensembles pareillement agencés; mais ici, chaque cas constitue un tableau particulier, unique, ne pouvant se trouver en rapport avec d'autres que suivant certaines caractéristiques fondamentales. La liberté du tracé, la fantaisie propre à chacun ne permet pas de déterminer des groupes et des catégories fixes; il a rlonc paru préférable de présenter un exemple type de chacun des aspects auxquels les possibilités de ces ensembles ont donné lieu.

Tout d'abord, ces figures utilisent des motifs appartenant tous au règne végétal; ot si, dans certains cas, le rinceau d'une liane ou d'un sarment se distingue nettement (pl. III/12; pl. IV/1), c'est cependant l'agencement réticulé d'un ensemble ramifère que l'on rencontrera le plus souvent. L'ambiguité des ramifications de ces ensembles pourrait mème les faire confondre avec un réseau de lignes droites aux motifs placés sur les nœuds (pl. III/1, 3, 4, 5) ainsi que sur les nœuds et à l'intérieur des mailles (pl. III/7), s'il n'y avait, en dépit de l'absence de feuilles, la souplesse des lignes evoquant davantage des tiges. On trouve cependant le cas d'une figure réticulée dont les nœuds, accusés par un petit bouton, déterminent des mailles raides et irrégulières renfermant un phlā cãn' (pl. III/2). Toutefois les motifs semblent le plus souvent régulièrement disposés et l'on peut généralement discerner des agencements diagonaux (notamment pl. IV/3); d'autres, plus rarement peut-être, s'ordonnent suivant les sinueuses rangées verticales d'une mème liane (pl. IV/7).

Le plus fréquemment, les ramages utilisent des phlā cān' à pétales en demipastille et se présentent suivant des tiges simplement gravées d'un trait (pl. III/9), ou figurées par un trait double (pl. III/3, 4, etc.). Dans ces ensembles, les phkā cān' peuvent avoir des pétales acuminés (pl. III/1, 5) et même larges et courts (pl. III/6) ; parfois des feuilles rehaussent plus particulièrement le motif lui-même (pl. III/9, 10). Les rameaux peuvent être figurés par de légers rinceaux (pl. III/11) dont les volutes s'insinuent parfois entre les motifs (pl. III/12), et peuvent même ordonner la figure suivant une disposition verticale (pl. IV/1). I)'ailleurs il est à remarquer que cette 
tendance à une organisation verticale, mème très discrète (pl. IV/2), se rencontre souvent. On trouve encore un tableau qui, singulièrement, présente sur une mème liane des phlia cān' et des motifs floriux de profil (pl. IV/4).

les motifs de profil, exclusivement raméaires, rlont le nombre de pétales n'est guère plus défini que ceux des phlä cãn', sont par excellence les fleurs des figures à ramages. Parfois rencontrés sans feuilles axillaires ( $\mathrm{pl}$. IV/5) ou avec des feuilles légèrement esquissées d'une simple virgule (pl. IV/6), ces ensembles paraissent plus particulièrement devoir placer dans leurs mailles des éléments plus simples considérés comme de jeunes pousses (pl. IT/3). Exceptionnellement, des possibilités analogues se rencontrent dans un ensemble de phlià cān' (pl. $\mathbb{N}^{\top} / 7$ ). Bien que le cas soit rare. les ramages se sont encore exprimés par d'autres motifs. On trouve ainsi le motif floral cilié (pl. IN/8) et un autre motif, constitué de deux anneaux concentriques, curieusement présentés suivant de courts pédicelles en virgule (pl. IV/9); ailleurs, c'est un ensemble de motifs formés d'une bague que rehaussent quatre longs petales (pl. IV/10). Et l'on trouve mème des figures dont le champ a été parsemé d'un légorer semis d'éléments circulaires, irrégulièrement disposés entre les mailles ramiformes (pl. IV $/ 11,12)$.

Les réseaux. Ce sont des figures qui utilisent des ensembles de lignes parallèles orthogonales. Ces lignes se dessinent en creux, lorsqu'elles sont gravées d'un simple trait, comme c'est le cas de la plupart des figures (pl. V/1, 2, 3, 4, etc.), mais peuvent également s'élargir et accuser un léger relief (pl. V/5, 8, 9, etc.); ces simples surfaces réticulées ordonnent le décor de nombreux ensembles. Le plus souvent, ces figures s'expriment avec des motifs intérieurs aux mailles. Elles utilisent à cet effet des carrés (pl. V/6, 7, 8,9), pouvant même constituer un ensemble de phkā cān' contiguë̈s (pl. V/13), des motifs circulaires (pl. $\mathrm{V} / 10,11,12)$, des petits motifs cruciformes (pl. V/14), et le plus souvent encore des phkā cain' (pl. V/15, 16, 17, 18) ponctuant les nœuds du réseau (pl. V/19,23) ou pouvint également se situer à l'intérieur et sur les nœuds des mailles d'un ensemble (pl. V/20, 21). On rencontre aussi certaines figures présentant un champ utilisé en réseau sur lequel se place soit un quadrillage (pl. V/23), soit un semis (pl. $1 / 22,24)$. En dernier lieu, signalons une figure s'exprimant suivant un entrelacs de deux réseaux imbriqués, aux nœuls timbrés d'un phliā cān' (pl. $\mathrm{V} / 2 \%)$.

\section{LE IEECOR ARCHITECTLRAL}

A partir d'Angkor Vat, les nombreuses figures que les Khmers ont utilisées pour l'ornementation de leurs monuments, dans toute leur richesse et leur diversité, ne. sortiront pas du cadre déjá précisé par l'ornementation des tissus, et pour cause : le léger relief de la plupart d'entre elles reproduit tres vaisemblablement des tissus 
de soie brochée dont on connaît d'ailleurs la présence dans les temples (1). Le nu des larges surfaces qu'offraient les monuments était particulièrement désigné pour former le champ d'un tel décor, et rette judicieuse utilisation s'est vue sourent confondue avee ce qui fut appelé l'" horreur du vide». En architecture, les figures illimitées ont été diversement utilisées ; généralement sculptés en taille d'épargne, elles se présentent selon la faible saillie d'une surface champlevée

On rencontre ce décor sur les stores des fausses fenètres, sur les façades, dans les demi-galeries et sur les tableaux de portes.

\section{I.ES STORES DES FAISSES FENÊTRFS.}

"La volonté de simplification des techniques du style du Bayon amène l'adoption (...) de faux stores laissant apparaître seulement le tiers inférieur de faux balustres" (2). Con certain nombre de ces stores a reçu un décor souvent semblable a colui des tissus déjà rencontrés sur les bas-reliefs (3). On y remarque en effet un semis droit (pl. VI/1), diagonal (pl. VI/2), un ensemble de bhĩ des avec l'indication d'un pan tombant (pl. l I/3) présentant parfois un décor différent (pl. l//4) et figurant peut-être l'envers du tissu. On trouve aussi un réseau diagonal de phkä cän'aux nœuds frappés d'un même motif plus petit (pl. VII/1).

On a pu remarquer que le décor des tissus relevés sur les bas-reliefs n’offre aucun exemple de figure utilisant des rercles sécants ou des médaillons, fort amployés par ailleurs. Il était des lors possible d'envisager quelques particularités propres aux cnsembles du décor architectural. Or, le cas des stores des fausses fenêtres est particulièrement intéressant à cet égard et laisse supposer que cette lacune du décor des bas-reliefs provient de l'étroitesse du champ à décorer qui n'autorisait pas le sculpteur à pousser très loin le détail. Lin effet, le tissu de ces stores offere des ensembles beaucoup plus fouillés et semblables, dans bien des cas, à l'ornementation des façades et même des tableaux de portes. Ceci permet de souligner la remarquable unite de l'ornementation khmère. On relère ainsi un ensemble de cercles sécants (pl. VII/2) dont chaque point d'intersection est marqué d'un phkä cãn'; à l'intérieur des cercless s'inscrit un fleuron cruciforme cantonné de quatre ou six pétales. (On trouve également des figures de cercles tangentiels dont les points de contact sont, la aussi, marqués d'un phkā cān' et qui présentent soit un simple motif floral (pl. VII/3), soit quatre bhĩ des opposés par la pointe (pl. VII/4). Le champ de ces ensembles, dans l'espace découpé par les médaillons, apparait toujours garni d'un phkä cān'.

1. (:f. B. Ph. Groslier, Indochine, Carrefour des Arts, Paris $196 \mathrm{I}$, p. $159 \mathrm{sqq}$.

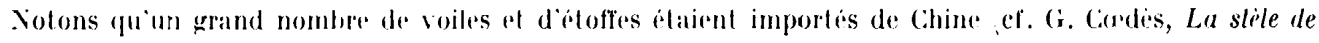
Ta Prohm, dans BLFEO VI, Hanoi 1906, p. 41 sqq., stances XLIV, I.XXVI, CIX!.

2) J. Boissclier, I.e Cambrelye, Manucl d'Archéologie d'Extrème-()rient, Asie du sud-Est, t. I, Paris 1966, p. $1 \times 2$.

3) Votons que ce même decor affecte également les rideaux des grandes arcalures de la gralerie-enceinte exterieure de Ta Prohm. 


\section{I.ES FACADES.}

"Lans les monuments au dereor particulierement riche. les murs de certains

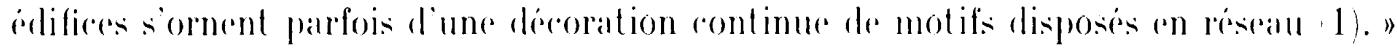

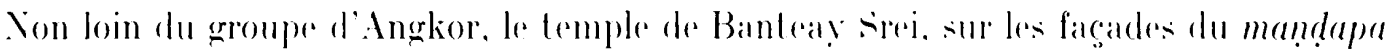
de son sanctuaire central. offre un réseatu droit figure par des bandes orthogenales franchement marequeses qui déterminent un ensemble de arres aldernativement

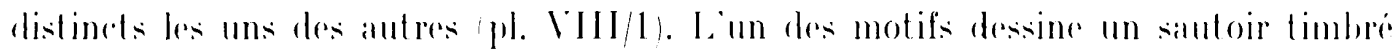
d'un gros bouton rentral dont les bras sont figurés pare un lleuron compose de deax

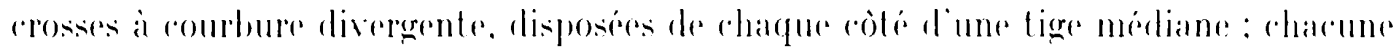

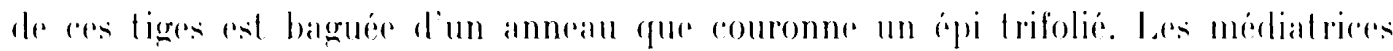

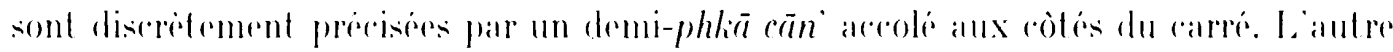

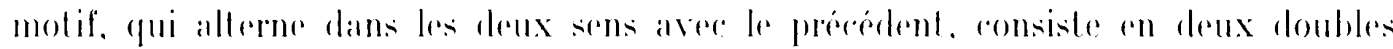

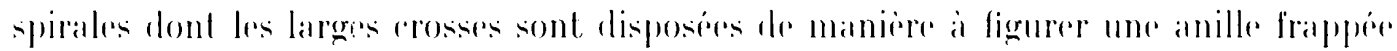

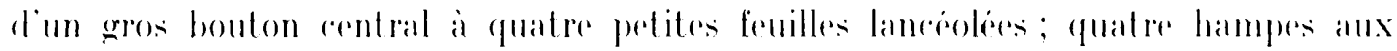
"xtremites tripenneres sinterealent discretement allx bras du sallutoir.

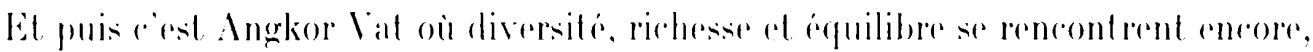

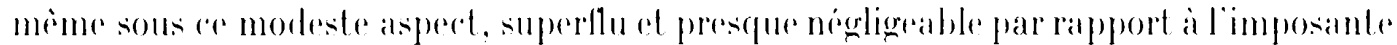
harmonie du lemple lui-mème. Le décor que viennent régulierement carcher les deralä

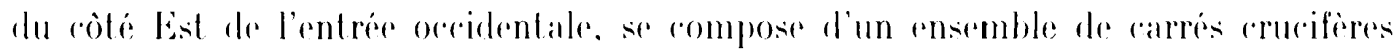

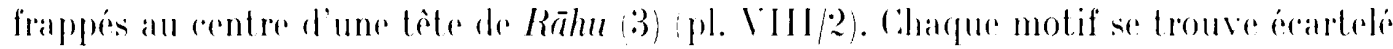
selon une croix potencere dont les bras dessinent une sorte dre calice serti llun liserage

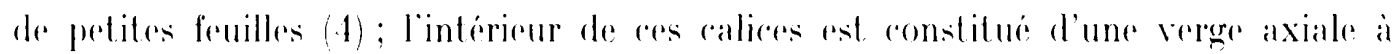

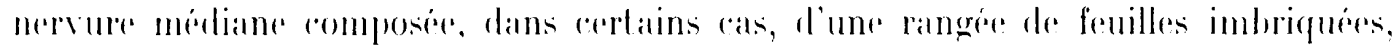

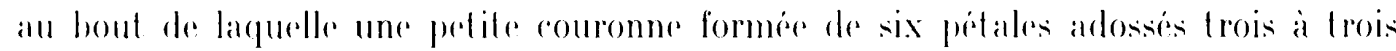
supporte un gland bobule; de la divergent deux rinceaux. Du mascaron central

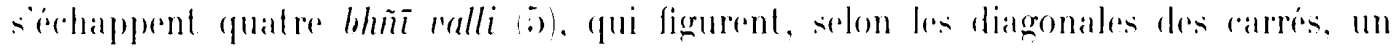
motif forme de quatere fuscalux opposés an santoir.

1 J. Buisselier. "a. c., p. 17\%.

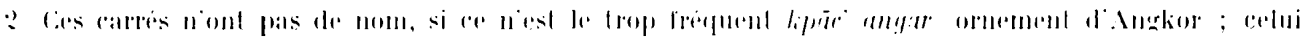

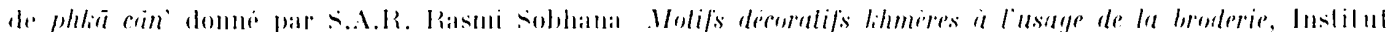

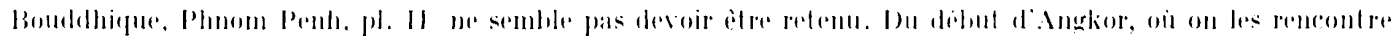

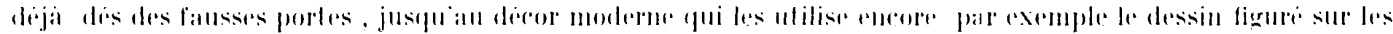

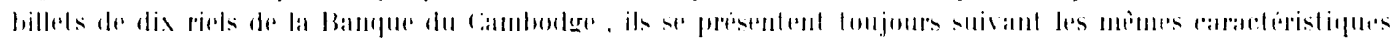

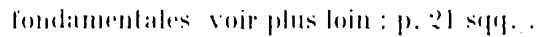

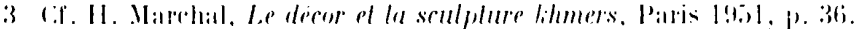

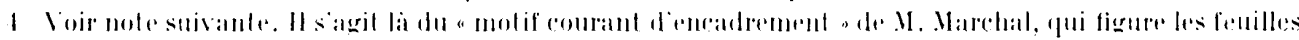

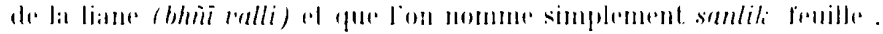

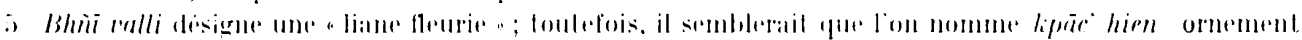

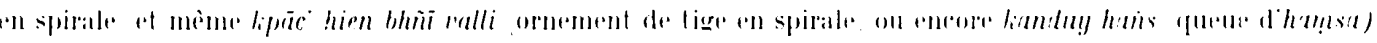

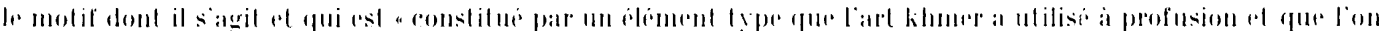

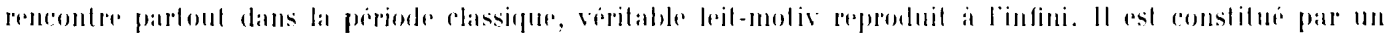

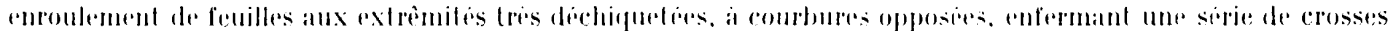

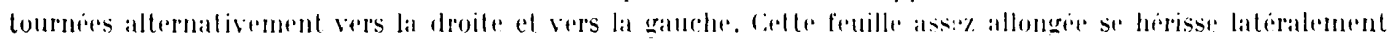


Les cing faux etages du même pavillon sont ornés sur loutes leurs faces d'un rnsemble de carres disposies an un réseau diagonal et eomportant chacun une nieder (eirculaire a huit lobes fortement bourrelés renfermant un personnage (pl. VIII/3); antour de eette niche se précise un motif cruciforme determine par quatre palmetles

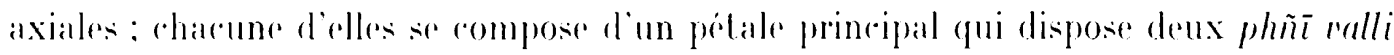
de chargue rote d'une courte hampe tricostée coiffée d'un gland lobulé ; suivant les mérliatriers des carrés of anx diagonales de la roix sintereale un motif plus simple figuré par un pétale et deux feuilles.

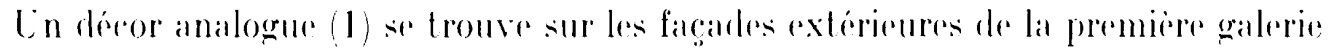
enceinte ainsi que sur colles des deux petites bibliothèques du deuxieme datage (pl. VIII/1). Disposé colte fois selon un résealu droil. il s'agit d'un ensemble de carrés a niche cemée de deux ou trois bourrelets circulaires qui dessinent huit lobes aux pointes parées d'un petit pétate ové et qui abrite également un personnagre.

Toujours au trobsieme hage. a l’interieur de la galerie pourtournante. la frise sur laquelle court une série d" "apsaras" a ete flemrie d'un semis régulier (2) place sur les nouds d'un reseall diagonal et présente suivant deux motifs se sureredant alternativement (p). IX/1) : chague élément figure un phlä cän', et le rythme a ele exprimé par l'arljonetion de huit pétales verticilles affectant un quatrefeuille sur deux.

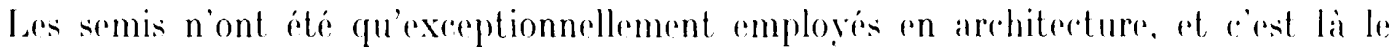
serul exemple rencontré.

Par contre, toujours a Angkor Vat, les ansembles les plus largement utilisés

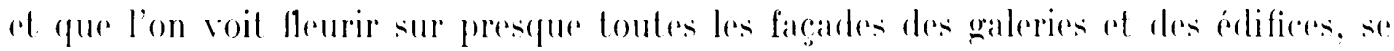
presentent suivant diverses figures a ramages (3).

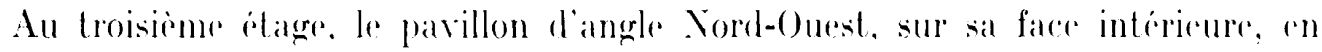
donme lexpression la plus simple (pl. IX/e) : le décor utilise uniquement le bhĩu des, qui marque les noeuds din reseatu ramillore a branchement diagonal ; le ceur de cer motif serempose d'un bouton central couronné diune pastille plus ou moins tréllée, lunulé ou flammier. ot surmonte un teiton alecusint le penflement pétiolaire; un pétale axial et plus important partage et dispose les autres symétriquement. Dans la grande majorité des rats rependant, deux élements sont utilisés, et le mème bhã dess

de pelits éments dallure analogne qui, un pen transformes, deviendront un motif conrant dencadrement, denticules ronds a double courbure que l'on rencontre aussi un peu partout " H. Marehal, Le temple de Prah

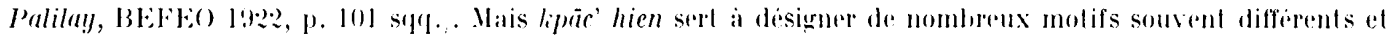
parfois mème des ensembles de motifs comme cux qui recourent par expmple le mandapa de Banleay srei

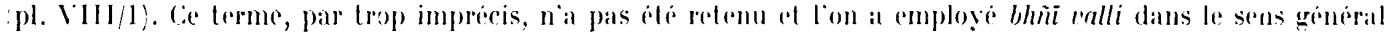
de "rinceau".

1) Notons que ces ensembles ont été encore utilisés pour "boucher "quelques surfaces nues des faux etages du sanctuaire central et des pavillons dangles, ainsi que de la face interieure de la premiere enceinte; la disposition en diagonale étant réservée pour los faux élages.

2) Ce genre de décor parait devoir se nommer kpäc' räy phkay iornement parsemé d'étoiles;, encore qua il regoive également le nom de lïrī itoile).

3) Ces ensembles peuvent être nommés kpäc' bhñi añgar lilīy fornement pustulé de fleurs d'Angkor/. 
se combine alors aver des fleurefles a trois, quatre ou ding pétales plus ou moins trilobes. La figure qui recouverentre aut res la face (Ouest du pavillon d'entrée ocerdental pl. $J X / 3)$ presente, suivant un réseau de rameaux en alecolade (1) a branchement diagronal et longrs pétales axillaires, un bhĩe des llanque de deux lleurettes qui sopposent suivant derux pérdicelles en quart de rond et söntercalent avee les éléments principaux. Exerptionnellement on reneontre une variante de cette figure pl. IX/4) qui présente inchus dans chaque maille et entere les fleurettes un autre motif semblable.

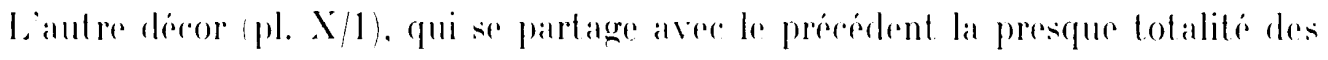
ramages. présente. toujours a lointérieur des mailles de la structure réticulée habituelle rt suivant le meme motif lloral, une petite fleur inversie au bout d'un ramuncule qui sarecole indifferemment à leun ou l'autre des pédonedules du branchement 2 ).

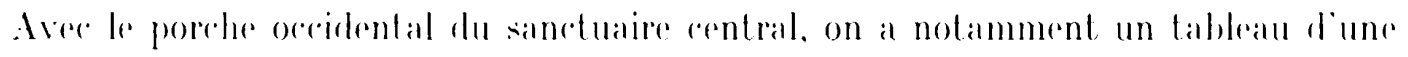

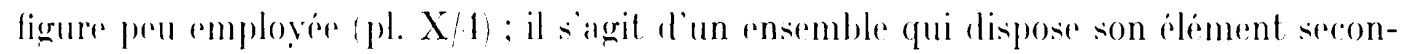

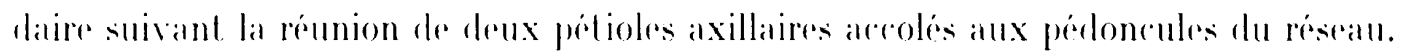

le pavillon d'aceses ocridental de la quatrieme enceinte offere exeptionnellement lexemple de quatre compositions uniques, tratés discretement sur la surface atroite de deux angles ot de deux ressauts de facade. Ces figures, aux structures singulieres. utilisent un phlia crän' feuillu, analogue à celui rencontré dans le semis du troisieme atage (pl. IX/1) et jusque-la inconnu dans les figures a ramages des façades d'Angkor Vat. Ic passage charretier Yord offre une figure fort complexe qui utilise le phkī cän' et la lleurette (pl. X/2) : suivant un ensemble droit, présentant un branchement diagonal régulierement et très curieusement interrompu, la figure utilise un motif principal composé de cinq pétales acuminés disposés autour d'un phkãa cān'; a l'interieur des mailles et comme s'alternant aree les motifs selon les diagonates, se trouve une fleurette tripétalée posée sur un pétiole a fort renflement runéiforme

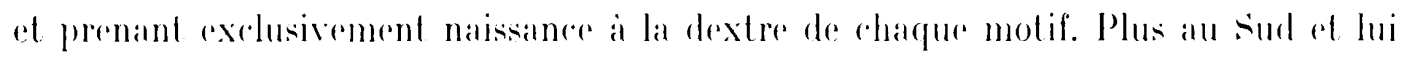

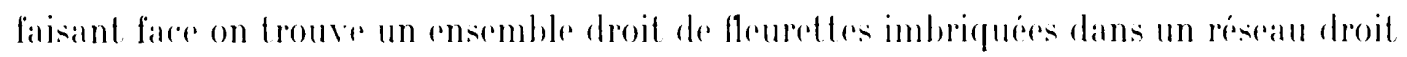

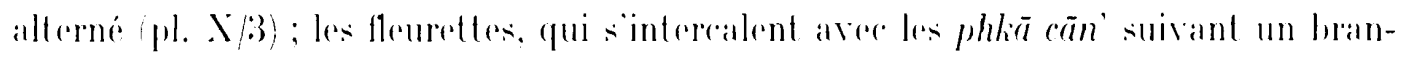

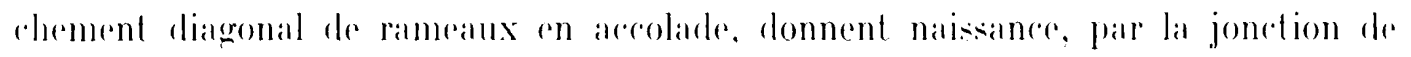

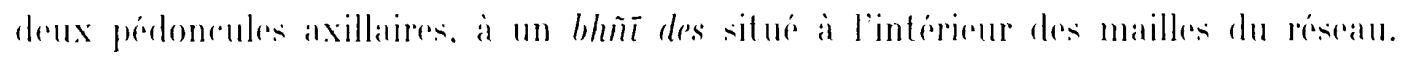

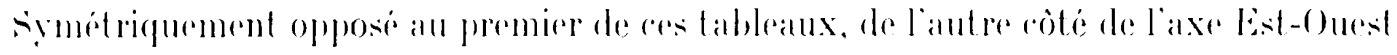

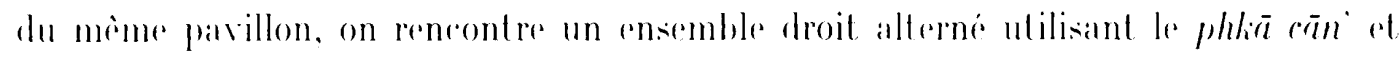

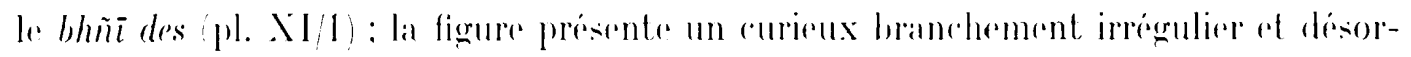

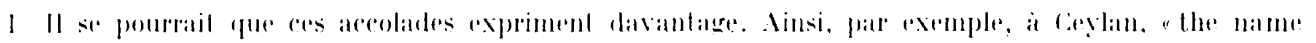

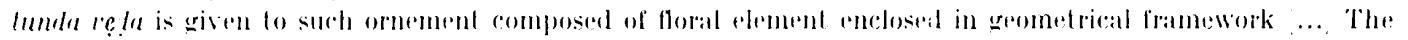

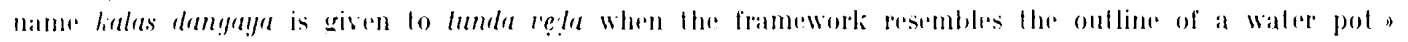

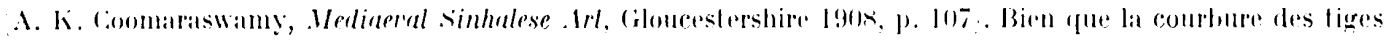

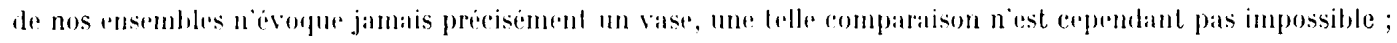
aucun indice nien a foutefois aulorisi l'application and figures d'Angkor.

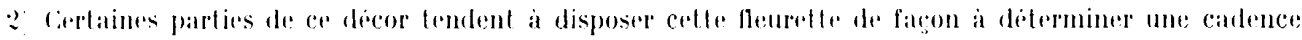
alternative selon l'aceolement successivement dextre et semestre de son peitiole sur les tiges du résuan. 
donné selon des rameaux inégaux à feuilles axillaires. Ies deux mèmes molifs se rencontrent encore (pl. XI/1), mais cette fois suivant un ensemble diagonal alterne que dispose un branchement régulier de rameatux verticaux at diagonaux.

Enfin, on trouve encore un ensemble se developpant suivant deux dimensions. Le déeor qui orne les facades du gopura Est ainsi que la partie médiane de l’édifiere central de Chausay Tevorla, presente un ensemble de carrés determines par un reseau de bandes orthogonales rehallssies d'un perlage de phlä cän' (pl. XI/2). Charque motif est ecartelé d'un sautoir formé de quatre fuseaux composes chacun de deux feuilles à crosses opposés of d'un epi médian; deux autres feuilles analogues en forme de crobsisant flanquent encore chaque fleuron, à moins quelles naffectent plus précisement une hampe aculéiforme. parfois triestée, qui sintercale aux bras du sautoir selon les médiatrices: le milieu rest frappé d'une grosse cocarde à deux zones roncentriques d'étamines et à bouton central.

\section{LLS DEMI-(iALERIES.}

Surtout a Angkor Vat. l'ornementation des demi-galeries llanquantes a ete l'objet d'une attention particulière : l'intrados des demi-voùtes, qui nétait masqué d'aucun plafond, s'orne d'un ensemble de rosaces; les revers d'architraves des demigaleries des première et quatrieme enceintes, dont les angles rentrants ne reçoivent pas d'étrésillon, sont garnis, dans l'espace ménagé all droit des piliers d'angles, de petits panneaux décoratifs (1) ; les demi-roùtes sont treminées par des demi-frontons recouverts de figures animées par des personnagers.

L'inlrades des demi-eoúles. A Angkor lat et dans les principaux temples du style du Bayon lintrados des demi-roùtes est recouvert d'un ensemble de rondeaux Langenticls (2) organisé suivant un réseau droit (pl. XI/3). Chanque médaillon figure une rosace de huit pétales seutiformes frappés discrètement à la base d'un petit motif trilobé; chacun de ces pétales est cerné d'un filet qu'aceuse encore un ourlet de petites feuilles convergeant vers la pointe. Au centre du motif règne un phlià cān' rehaussé de huit pétales en demi-pastille, autour duquel se trouve un galon circulaire polylobé dont les huit pointes disposent des pétales qui alternent avec une série de

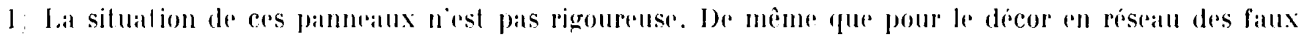

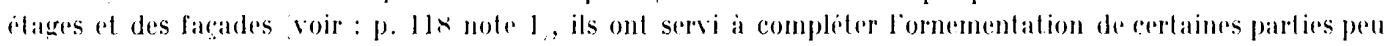
commodes à unifier au décor de lensemble. Ainsi on les trouve egalement dans les demi-galeries des escaliers d'acces au deuxiene etage de la galerix cruciforme. Ils s'y rencontrent sans regularile ni precision et mordent mème parfois sur l'étrésillon. Jotons, au deuxieme niveau de lescalier méridional, un curieux décor utilisant des rinceaux des bhï des à dixiloppernent horizontal.

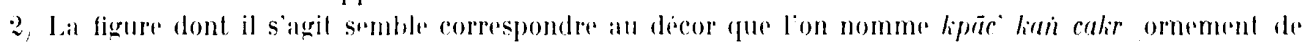

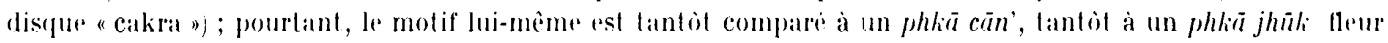

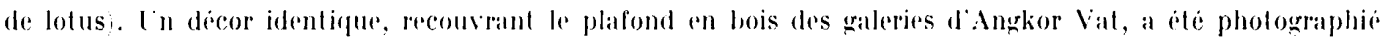

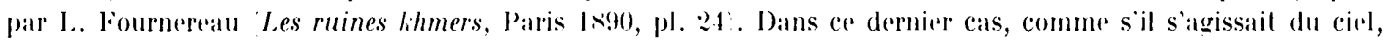
le decor se nomme lipäc jhül pliking ornement etoile de lotus: 
petits tétons. Le tout se trouve circonscrit par une large bande perlée circulaire dont les lobes correspondent à la rosace de façon que leurs pointes disposent dans les espaces laissés libres un motif à trois pétales lobulés. Sur le champ du décor, dans les nus délimités par les cercles, se trouve un motif (1) cruciforme à huit branches au centre timbré d'un phliā cān' ; Les bras axuels sont figurés par un ensemble de pétales acuminés, plus ou moins ordonnés, de façon à constituer, souvent sans précision, deux motifs de cinq pétales avec fleurettes latérales; les branches diagonales, plus courtes, prennent naissance au bout d'une longue feuille et déterminent un motif composé principalement d'un calice festonné surmontant deux pétales.

La face inlérieure des archilraves. A l'entrée occidentale et au troisième étane d'Angkor Vat, le revers d'architrave des demi-galeries a été discrètement orné de petits tableaux. La première enceinte ainsi que le sanctuaire central offrent des ensembles de médaillons circulaires renfermant des salv hans (2) (pl. XII/1). Ces médaillons sont orientés suivant l'ouverture d'un rameau en spirale qui, dans la majorité des cas, dispose les motifs de façon à les opposer alternativement en rangées verticales; le champ du décor est garni de phkã cān' (3). Le gopura Ouest de la quatrième enceinte dont le décor est d'une délicatesse et d'un fini particuliers offre des panneaux d'architrave organisés suivant un système d'entrelacs ( $\mathrm{pl}$. XII/2). Ils présentent un ensemble de médaillons tangentiels qui s'entrelacent selon le jeu de quatre rameaux en quart de rond et dont les points de contact, marqués par des anneaux à bouton central, distribuent, à l'intérieur de chaque motif, quatre feuilles tripennées axiales, opposées par la pointe.

Les demi-frontons. Toujours à l'intérieur des demi-galeries d'Angkor Vat, les demi-frontons ont été décorés sur leurs deux faces de tableaux organisés suivant un réseau droit de médaillons garnis de personnages. D'une façon générale, ces tableaux retracent quelques principaux épisodes de légendes célèbres, et l'on y remarque souvent des personnages qui s'organisent autour d'un médaillon principal (pl. XII/3, 4; pl. XIII/4), ou encore s'animent selon le jeu simple d'une disposition symétrique (pl. XIII/1, 2, 3). Les cercles qui constituent les médaillons sont parfois bordés à l'intérieur d'un collier de pétales orientés (pl. XIII/2) ou, plus généralement peutètre (4), ils dessinent huit lobules dont les pointes disposent plus ou moins régulièrement des pétales et des fleurettes (pl. XII/4; pl. XIII/1); sur le champ du décor un fleuron cruciforme se composant d'un phlā cän' et de qualre palmetles axuelles

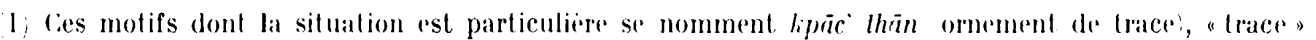
ilant pris dans le sens d'espace, de lieu ske sthäna, pali thinnt delimite par le contour des motifs.

2 , Sall haris ou harisi, c'est-d-dire l'oiseau hamsal.

3. le decor de ces pameaux est amalogue à celui des tableaux de baies du mème elage voir plus loin : p. 123;.

1) Desquamations et effritement du gres ont rendu la majorite de ces demi-frontons illisibles ; seul un nombre restreint a pu être consideri. 
tripennées, s'intercale avec les cercles selon les diagonales. Mais ceci ne s'applique pas aux demi-frontons de l'entrée occidentale qui présentent quelques différences : ils ont utilisé des entrelacs semblables à ceux des panneaux d'architrave; toutefois, ils se précisent suivant huit rameaux plus courts dont la jonction, exempte cette fois des rameaux à bouton central, distribue à l'intérieur des motifs quelques feuilles dentelées beaucoup plus simples; là encore un phkā cān' marque l'interstice des motifs (Pl. XII/3 ; pl. XIII/3). D'autres demi-frontons de ce même pavillon ont utilisé des mérlaillons ovoïdes polylobés et ourlés de petites feuilles, plus ou moins entrelacés (pl. XIII/4), analogues à ceux employés également pour quelques revers de frontons.

\section{LES TABLEALX DE: BAIES.}

A partir du style d'Angkor Vat, les tableaux de baies se sont enrichis d'un décor en faible saillie, d'une délicatesse exceptionnelle (1). Ces ornements ont néanmoin: suivi la tendance de l'évolution générale et s'appauvrissent vers la fin des monuments du style du Bayon. Dans la plupart des cas, ce décor n'affecte que les édifices principaux des temples, et plus spécialement encore, certaines baies de ces édifices, dont il recourre alors les tableaux latéraux et supérieurs des portes et des fenêtres (2).

D'une façon générale, et malgré quelques ensembles plus ou moins particuliers (3), l'expression de ces ornements peut toujours se ramener à celle d'un réseau droit de médaillons circulaires, au champ frappé de fleurons cruciformes, et llanqué d'un lisérage de bordure latérale (4). Les mondes végétal, animal et humain, ont eté diversement traités sans que l'on puisse accorder la préséance à l'un d'eux, encore que, ut ceci peut être significatif, tous trois se soient également exprimés selon les souples et régulières volutes de lianes à rameaux feuillus.

Le monde végélal. Il a exclusivement utilisé le bhñi des, qui, dans des ensembles de médaillons généralement orientés selon l'ouverture de rameaux en spirale, sert à constituer des figures extrèmement variées. Sauf à Angkor Vat où elles se rencontrent plus particulièrement suivant une composition de quatre éléments axiaux opposés par la pointe (pl. XIV/4), ces figures ne présentent souvent que des motifs à une

1 Cf. I. Finot, V. Goloubew, G. Codes, le temple d In!lior Val, t. II, Paris 1930, Pl. 167 à 176.

$\because$ Il ne salurail être question de traîter ici ce decor dont la variêté des structures et des motifs employics ainsi que le grand nombre de tableaux à considerer imposera une blude spécialo -.. 3400 tableaux environ, d'une largeur do 30 a $90 \mathrm{~cm}$ et d'unc hauteur allant jusque jo metres, pour le seul groupe d'Angkor ch sans compler les tab]eaux superieurs dont l'ornementation ressort, encore qu'avec certaines variantes, de celle des montants. Toutefois, comme l'on ne peut, sans grave lacune, priver cette eblude de la source la plus riche des figures illimities. el comme on doit, par ailleurs redure son envereure all cadre doun article, on me dommera ici gu'un apercin de ce decor.

3) Notamment des ramages à bhĭ des analogues daus plusieurs cas à ceux des facades d'Angkor Val.

4) Nolons loutefois que la troisieme période des monuments du style du Bayon ce. Ph . Stern, Les Monumenls hihmers du slyle du Bayon et Jayayarman VII, Paris 1965, p. 40) a riduit lexpression du decor de ces tablaux de haies à des ensembles se developpant dans une seule direction. 
seule fleur (pl. XIV/1), ou se composent encore de médaillons à deux (1) (pl. XIV/2) ou trois (pl. XIV/3) éléments diversement agencés.

Le monde animal. Encore que, dispersés au rythme des rinceaux historiés, de nombreux animaux divers se rencontrent çà et là, le monde animal semble avoir été plus spécialement représenté par deux sortes de motifs : le salv indri $(2)$ et le salv haris. Le premier de ces motifs se présente toujours suivant une composition circulaire de deux oiseaux imbriqués (3), et donne lieu à des ensembles de médaillons disposés en réseau droit (pl. XV/1) (4), qui, avec le style du Bayon, furent traités plus spécialement suivant un large rinceau à développement vertical (j)). Le deuxième motif a été notamment utilisé à Angkor Vat et en particulier au troisième étage; toutes les baies de cette première enceinte en sont recouvertes et, dans des ensembles de rinceaux aux rameaux diversement orientés, il exprime le rythme complexe de compositions précises et variées (6) (pl. XV/2).

Le monde humain. Il a été représenté avec beaucoup de fantaisie par des hommes rt des dieux au sein de compositions fort diverses. C'es sculptures délicates, à l'expression réaliste et au détail savoureux, utilisent un grand choix de motifs. Et, de leur habile distribution, se précise une scène, dont le décor et les acteurs illustrent les épisodes célèbres de textes épiques (7). A Angkor Vat, ces tableaux se présentent

(1) Votons que l'élément de ces médaillons biflores dont la corolle campaniforme, large et lobulée, differe du bhni des habituel, s'apparente a bien des égards aux motifs du décor floral des boîtes in porcelaine chinoises SSong du Sud, Yuan trouvés au Cambodge. D'ailleurs, ces médaillons biflores dont la structure s'apparente a celle des médaillons de satl: indri voir note suivante) se retrouvent eux-mêmes en Chine : la belle ornementation des céramiques Yue cf. Wan-ly chen, Yüeh Ch'i T"u L.u, Ilangchow 1937, planches 1, 57, ainsi que le decor des Céladons du Nord ot des Ying-ls'ing icf. Basil Gray, Early Chinese Pollery and Porcelain, London 1953, planches 69, $76 \mathrm{~B}$ in offrent quelques beaux excmples.

2. On parle parfois de "motif sassanide a a propos de ces figures cf. H. Marchal, Les lemples de.tnglior, Paris 1955, p. 50 . La dynastie des T'ang les aurait alors recues avec les refugiés perses, ce qui n'est pas sans coincider avec leur apparilion dans l'art chinois. De fait, avec divers antres molifs composis sur un schema analogue, c'est en Chine que cette figure reçut sont plus grand développement ; et cela n'est peut-être pas sans quelques rapports avec le fait que leur structure figure un dessin qui reproduit le diagramme du T"ai $\mathrm{Ki}$. Quoi qu'il an soit, le decor de la poreelaine Yue de Tchang-lin hou et de Yue-yao ice. Wan-li Cihen, o.c., planches $43,44,47,4 x, 73,74$, ainsi que celui des ceramiques de la fin des Cinq Dynaslies 'ef. C. st. G. M. Gompertz, Chinese Celadon Wares, London 195x, planches 12,15$)$, en donnent particulierement de riches exemples.

(3) bäm lihäm gnä, * qui se mordent mutuellement ».

4) Les brocarts chinois de l'époque Song montrent souvent un tel decor à medaillons festonnés et bordure vegribale; les motifs de ces brocarts s'enroulent dans un sens ou dans l'autre de sorte que l'ensemble s'ordonne suivant le rythme des rangérs ou des motifs qui s'opposent alternativement les uns aux autres. Par exemple, le "brocart d'or avec dragons en médaillons et jeu de fond végétal" dans W. Speiser, Chine, Espril el Socięte, P'aris 1960, p. 173, s’anime ston une cadence où les rangées horizontales s'opposent entre elles. Ce rythme est precisement celui que figurent le plus souvent les ensembles de sate indri d'Angkor Vat voir : pl. .X\%, fig. 1;.

(5) Les médaillons de ces ensembles présentent généralement un couplo doiseaux à qurur respectivement raide ot ondulée. Ce détail se retrouve avec une remarquable précision en Chine, notamment sur certains miroirs de bronze de la fin des "T"ang miroir 25.491 du Musée L. Finot a Hanoi, C. L. L Vandermeersch, les Miroirs de bronze du Musee de Hanoi, Publ. FlFo, vol. XINI.

6) La diversile du couple spirale-oiseau, selon lequel s'organise l'ornementation de ce's tahleatux, determine huil sortes de cadences, précisée chacune par differents groupements de combinaisons particulieres.

(7) "... plusieurs de ces sculptures) restent provisoirement refractaires a l'identificalion. Disons tout de suite que celles qui se laissent interpreter appartiennent aux mêmes cycles que les grands bas-reliefs et présentent peu de sujets nouveaux" G. Condes, seconde elude sur les bas-reliefs d'Anglior Vat, BEFE() 1913, VI, p. 1). 
en plusieurs étages illustrant chacun une scène particulière (pl. XVI) (1), alors qu'avec le style du Bayon ils tendent à se ramener à l'expression d'une composition unique (pl. XVII/1). Ces figures peuvent aussi s'animer selon le jeu de personnages dont les mouvements précisent plus simplement des scènes de batailles ou de chasse (2). Parfois encore, clles utilisent des compositions symétriques dans lesquelles se groupent et s'ordonnent des personnages ainsi que d'autres motifs, suivant le rythme de dispositions variées (pl. XVII/2).

\section{IDEUXIEME PARTIE}

\section{L'ORNEMENTATION}

De mème que les scènes légendaires ou mythologiques sculptées sur les bas-reliefs et les frontons ont surtout pour but de manifester le monde divin (3), les ensembles ornementaux ne se limitent pas, cux non plus, à la seule figuration d'un décor: ils traduisent les lois de rythme et d'équilibre présidant à l'harmonieuse composition d'un tout.

On aura déjà pu remarquer que les figures précédentes ne se bornaient pas à la description donnée pour chacune d'elles ; les figures symétriques ont, en effet, plusieurs aspects et sont susceptibles d'autant d'interprétation. A Angkor, ces divers aspects, apparemment tous conciliables en un certain nombre de couples réductibles, se trouvent précisés avec les figures à carreaux, à carreaux alternés, à médaillons circulaires et à ramages.

1) Notons, a tin de fixer les idees, mais sans vouloir pour l'instant entrer daus le detail de l'iconographe de ces piedroits, que les scenes représentees sur le tibleatu de la pl. XVI, illustrent des thrmes vichnoutes.

2: Encore que le rythme de personnages opposes les uns aux autres dans des allitudes de combat, on bien encore, allernant avec de's animaux qu'il pourchassent, détermine, suivant le jeu de diverses combinaisons. des figures suffisamment intéressantes pour qu il ne soit pas necessaire d'y rechercher d'autres signifleations, il n'est cependant pas impossible d'y trouver un autre aspect, une sorte de légrtimation iconographique de ces ensembles aniconiques. Il s'agit des motifs dicoratifs dont fe protolype remonte à lexpression simplifie d'un archétype légendaire. A. Foucher, dans l'art du Gandhara, a êtabli un rapport analogue à propos d'une sciole "une fois pour toutes stéréotypée et machinalement reproduite dans un but pieusement ornemental. Nous croyons cependant, poursuit $\mathrm{A}$. Foucher, quion n'en peut expliquer l'origine qu'à condition de la chercher dans les bas-reliefs où cette disposition et cette attitude réciprocque des personnages étaient déterminées par le sujet. el imposées d'oflice à l'artiste par la tradition " L'Arl gréco-bouddhique du (iandhara, 1. I, Paris 1905, p. 426).

3) G. Codes, Pour mieux comprendre Anglior, Paris 1947, p. 106. Dans le même ordre d’idées, on peut citer P. Mus : "chaque élément du microcosme architectural correspondant à une partic du cosmos, les images dont le premier se couvre illustrent done surtout le second" Barabudur, BEFEO XXXII, p. 271). 


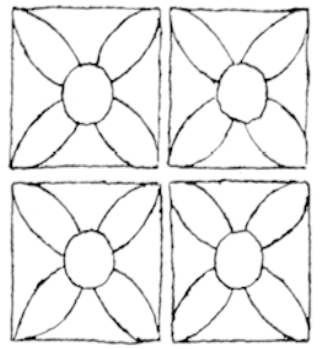

Fig. 1

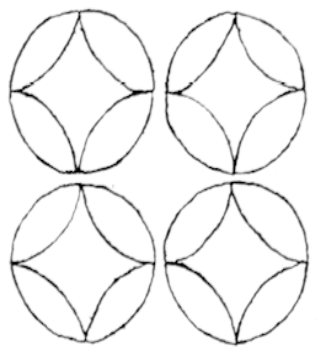

Fig. 4

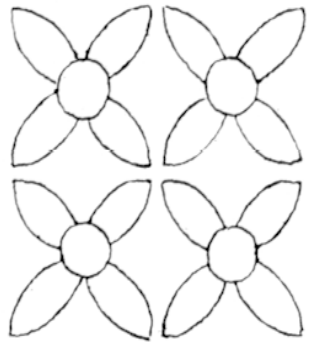

Fig. 2

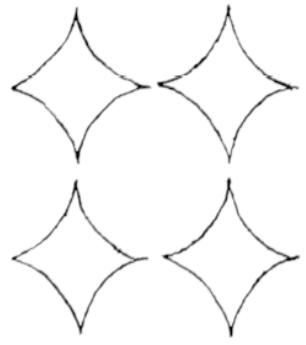

Fig. 5

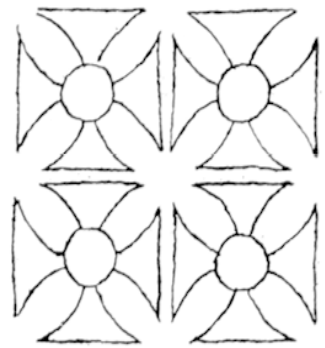

Fig. 3

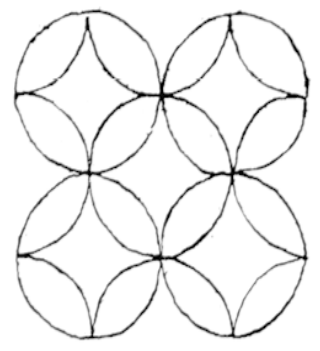

liig. 6

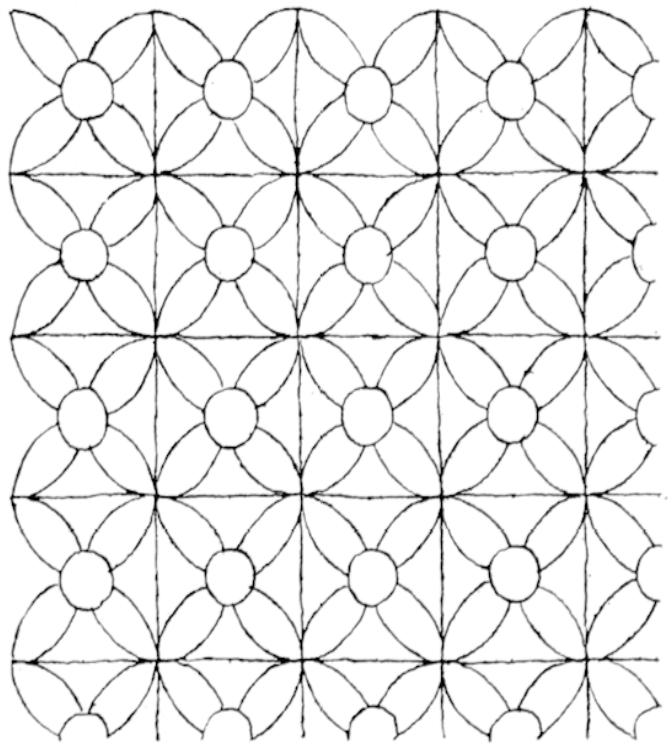

Fig. 7

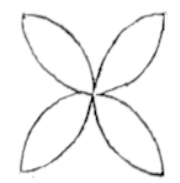

Figr. 8

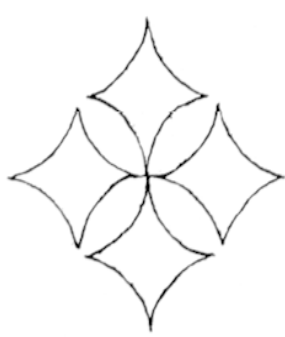

Fig. 9 


\section{Les figlres a carreaux.}

Une feuille de papier quadrillé donne un excellent exemple d'une figure illimitée qui se présente suivanl deux aspects, l'un el l'aulre indissociablement constitutifs de cette figure; le premier est un ensemble de carrés reproduits sans fin dans deux directions; le second est un réseau de droites orthogonales à mailles quadratiques. De là, on pourra mettre l'accent sur l'un ou l'autre de ces points de vue, en soulignant particulièrement l'aspect correspondant. C'est le cas, par exemple, de la figure à carreaux que l'on trouve sur les façades du troisième étage d'Angkor Vat (pl. VIII/4) dans laquelle, bien qu'à un degré moindre, l'ensemble de droites y est toujours nettement perceptible. Le décor de Chausey Tevoda ( $\mathrm{pl}$. XI/2) donne un exemple, somme toute peu courant, de l'excellent parti tiré à valeur égale des deux possibilités d'une telle figure : le réseau de droite figuré en relief a été expressément déterminé par un perlage de phkā cān', alors que les espaces ménagés dans les mailles étaient également garnis d'un riche motif.

Ainsi, pour exprimer le rythme d'un ensemble, on peut fort bien utiliser des motifs identiques. L'harmonie de la figure sera alors en rapport avec celle du motif lui-même qui possède son équilibre propre. C'est le cas notamment des motifs quadratiques que l'on trouve à Angkor Vat (pl. VIII/2, 3,4) ainsi qu'à Chausay Tevodı (pl. XI/2). Le centre, généralement exploité en un large motif circulaire, distribue, selon les diagonales, quatre fleurons fusiformes et, selon les médiatrices, quatre hampes aux extrémités festonnées. Chacun d'eux exploite les mêmes éléments : un centre, une croix, un sautoir, et se ramène essentiellement à un schéma qui précise le centre et les axes de symétrie du carré. Des unions de ces éléments entre cux, assemblés dans une même figure, vont se dégager de nombreux aspects. Prenons comme exemple le décor de l'entrée occidentale d'Angkor Vat (Pl. VIII/2), particulièrement explicite à cet ègard. La figure, on l'a vu, est un ensemble de carrés crucifères (fig. 1). Ces motifs, décomposés en leurs éléments, précisent un ensemble de croix de SaintAndré (fig. 2) et un ensemble de croix de Malte (fig. 3). Si, par translation, on amène en coïncidence les axes de symétrie des motifs avec les côtés des carrés, on détermine d'autres éléments, implicitement contenus dans les précédents, qui précisent un ensemble d'anneaux circulaires composés de quatre fuseaux (fig. 4) et un ensemble de carrés curvilignes (fig. ō). De là, la complémentarité de ces deux ensembles déterminera une figure de cercles intersécants (fig. 6) dont les éléments, associés aux motifs de base, s'opposeront alternativement les uns les autres, selon qu'ils seront coupés et parés au chef et à la base d'une tête de $R a \bar{h} u$, ou bien partis et flanqués du mascaron (fig. 7). Une transfiguration plus complète s'obtiendra encore, si, au lieu des axes, l'on considère le centre de symétrie de chaque motif : soit le deuxième aspect du décor, c'est-à-dire, non plus les carrés mais l'ensemble de droites qu'ils déterminent; toujours par translation, amenons le centre des motifs à se confondre avec les nœuds du quadrillage obtenu; on obtient ainsi d'autres ensembles, dont les éléments seront 
un autre sautoir (fig. 8) et une autre croix (fig. 9). Le jeu de tous ces aspects se prêtera à un nombre indéfini de combinaisons qui pourront être vues comme illusoires par rapport à l'ensemble considéré.

La figure centrale de ces motifs, dont la nature particulière de chacune (Rähu, phkā cān', etc.) individualise en quelque sorte des structures analogues, peut encore ajouter à la subtilité de ces ensembles : le décor de certains des faux étages et des façades d'Angkor Vat (pl. VIII/3,4) précise en effet ces mêmes motifs quadrangulaires dont, cette fois, le cœur reçoit un médaillon garni d'un personnage. Et suivant l'attitude de ce dernier, s'exprimeront encore diverses carlences en plus des autres aspects précédemment énoncés.

Les petits panneaux d'architrave des demi-galeries du gopura occidental offrent également un bel exemple de cette subtilité (pl. XIl/2). L'aspect premier selon lequel l'ensemble a été figuré ne laisse aucun doute : il s'agit du médaillon quadriflore, déjà fréquent au Baphuon et que l'on rencontre un peu partoul à Angkor Vat (Pl. XIT/2). Pourtant c'est un réseau diagonal, constitué par le joint des feuilles, qui apparaît en premier lieu, déterminant ainsi des carrés qui précisent un ensemble de motifs rhomboïdes alternativement debout et couchés; les motifs peurent également se centrer sur les points de trace des médaillons et, suivant un groupe de quatre rameaux entrelacés, présenter un ensemble de motifs cruciformes.

\section{LES FIGLRES A C.ARREALX ALTERNÉs.}

Mais le rythme d'une figure utilise également le développement de deux motifs alternés (1), dont l'opposition, qui peut se traduire de différentes manières (creux et saillants, ornements et nus, vides et pleins, etc.), pré(ise, avec Banteay Srei, le développement de deux motifs différemment décorés. Cet ensemble, qui trouve son expression schématique dans la figure du damier, possède la même structure que celle d'une feuille quadrillée; mais là, au couple droite-carré, s'est imposée l'opposition du noir et du blanc. Ces deux éléments qui précisent ainsi une première alternance, en déterminent encore une seconde qui affecte la structure même du décor : en effet une figure à deux éléments implique un ensemble alterné (fig. 10 ou 10') et, inversement disposés, deux ensembles imbriqués (fig. 11 ou 11') ; le premier pourra être vu comme alternant avec le second, lui-même constitué de deux ensembles opposés.

1 En dehors de la diversité d'expression des lableaux a personnages pl. XV'l les figures illimités composées selon plus de deux élements expressément figurés ne se rencontrent pas à Angkor, si ce n'est le decor a ramage de l'angle du passage . .ord de l'entrée occidentale d'Angkor Vat pl. X/3j. Signalons toutefois la frise a hauteur dappui des galeries de celle même entrée occidentale : trois éléments des apsaras suivant trois altitudes) se reproduisent indéfiniment et par ordre le long du mur. Mais il s'agit là d'un ensemble illimite dans une seule direction. Des lors que le developpement d'une figure a plusieurs éléments se fait suivant deux dimensions, chaque element occupera le centre des mailles du réseau que precise l'ensemble dans lépuel il s'imbrique. Celte figure pourra ainsi recevoir un nombre indéfini de motifs : tout nowvel élément déterminera un ensemble cqui, inversant la disposition genérale de la figure, s y opposera sans s'y confondre. I) autres répartitions sont evidemment possibles. Mais lat figure se bornera alors à preciser l'alternance de groupes diversement combines, relevant davantage de la succession d'ensembles illimiles à une seule direction. 


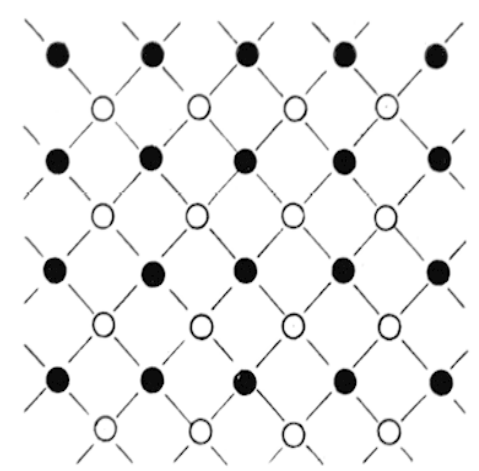

Fig. 10

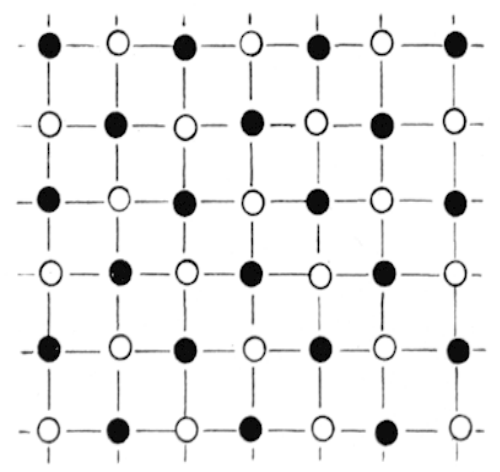

Fig. 10'

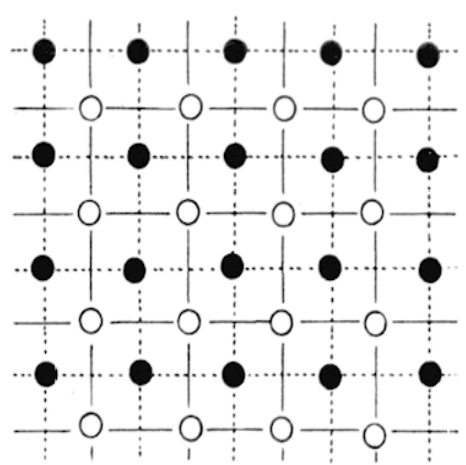

Fig. 11

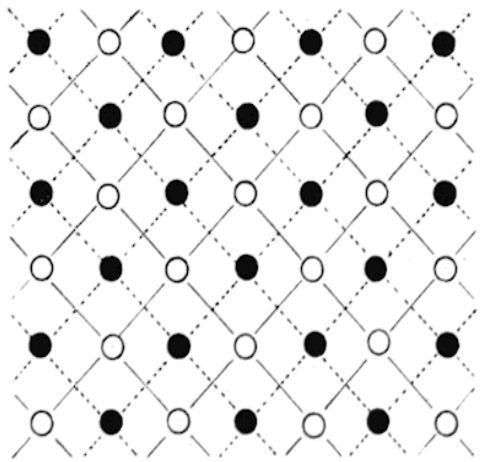

Fig. 11'

\section{LES Figires a MÉdAillons circilairfs.}

On sait que les carrés sont, avec les triangles équilatéraux et les hexagones que l'on ne rencontre pas à Angkor, les seules figures pouvant recouvrir entièrement une surface. ('e sont là des cas particuliers, et la notion de "fond " qu'ils mettent en jeu ne s'exprime pas directement. En effet, dans le schéma du damier - ensemble noir sur fond blanc ou blanc sur fond noir -- la trace des motifs est égale aux motifs rux-mèmes, d'où la nécessité, pour en déterminer l'alternance, d'une différenciation supplémentaire. Par contre, les ensembles de cercles tangentiels que l'on trouve a Angkor (pl. XI/3) utilisent pleinement cette possibilité fondamentale et la dualiti s'impose d'elle-même : aux cercles s'oppose le quaternaire des carrés (1). Il apparait, en effet, que les motifs du deuxième réseau, c'est-à-dire ceux que l'on peut dire découpés

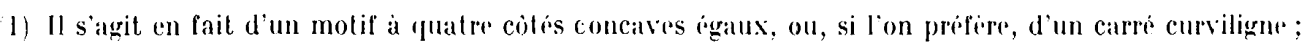
mais l'intérêl qu'il y a à l'assimiler au carró, en raison de l'idée de "quaternaire "que ce dernier impliquer, semble autoriser a considerer cette imprécision comme négligeable. De plus une croix s'y inscrit généralement. ce qui justifie, ne serait-ce alors que de ce point de vue, une telle association. 
dans l'espace laissé par les motifs du premier, se présentent toujours comme le "contraire " des autres (1). Et dans tous les cas, encore que plus ou moins appareillés peut-être, des couples pourront se discerner.

Mais dans certains ensembles, le couple, qui néanmoins subsiste, s'estompe au bénéfice d'un seul élément. Les figures à médaillons en sont l'exemple-type : elles s'expriment plus particulièrement suivant les motifs eux-mêmes, qui déterminent alors, selon la nature de leurs éléments constitutifs, le mouvement et le rythme du tableau. Par exemple, les ensembles de salv hans (pl. XV/2) combinent la direction indiquée par le bee de l'oiseau et celle de la spirale de chaque motif ; l'enroulement des médaillons florifères de Ta Prohm (PI. XIV/1) détermine un certain mouvement, etc. Ces ensembles expriment également le rythme particulier des scènes légendaires. Le's motifs s'ordonnent alors, selon la rigueur d'une structure symétrique qui distribue les divers èléments nécessaires à la projection graphique de chaque scène. La narration sidentifie ainsi à ce que serail "elle d'une "bande dessinèe" à deux dimensions : le sens de la lecture n'est pas déterminé ; il correspond au déroulement de l'action dont les différentes phases ne sont pas nécessairement successives mais peuvent tout aussi bien se developper simultanément.

\section{LAS FIGIRES a RaMagies.}

Les semis offrent la possibilité particulière d'utiliser des motifs ne présentant pas nécessiairement le caractère géométrique (2), et ceci parce qu'ils parsèment leurs éléments sur une surface stérile et désormais inutilisée (3). Cette restriction fondamentale s'est trouvée compensée par les possibilités de branchement des figures à ramages (4). Les ressources qu'offrait la perception de la pluralité constitutive d'un tableau - alternance d'aspects (carrés et droites orthogonales, sautoir chargé au rentre et sautoir bourdonné, etc.), alternance d'ensemble (disposition droite et diagonale, noir et blane, etc.), alternance de nature (cercles et carrés, girations contraires, etc.) -... se retrouvent maintenant dans celle du développement précisé

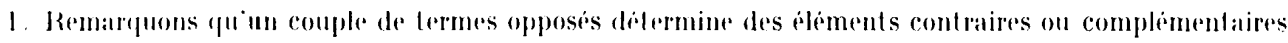

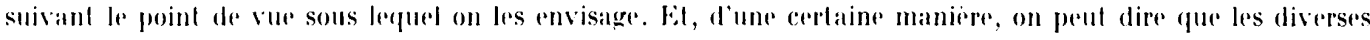
formes d'expression de ce "contraire" symbolisent aulant de muances dont est susceptible l'opposition de deus iliments complementaires.

$\because$ les ligures precidentes ansembles de carres, otc devaient, pour utiliser de tels molifs, recourir a l'arlifice du medaillon.

3. A. K. Coomaraswamy, o. .., p. 110, note en effet : "This arrangement of floral elements over an invisible framwork to cover space ... is closely allied to typical landa regla voir:p. 119, note l) from which it differs in the omission of the framework, and in that the flomb elements are more freety treated, not having lo occupy such defimed spaces".

1. F. 1). K. Bosch, The Golden Germ, S-gravenhagur 1960, p. I6i3, suivant difterentes comparaisons aver des ensembles analogurs que lon trouve "n Indonésie el d'apres, semblr-t-il, le beau ramage à persomnages de Lolei qui presente, il est vai, quedques singularites que l'on ne lroure pas a Angkor classe ces motifs.

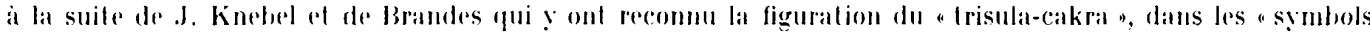

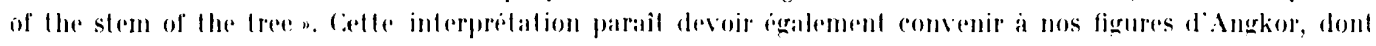

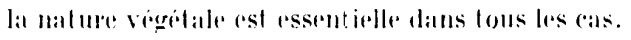


par ces nouvelles figures. Ainsi, en plus des diverses considérations inhérentes aux ensembles symétriques, se précisent certaines nuances particulières (irrégularité de la fig. 1, pl. XI ; les diagonales et la verticale de la fig. 4, pl. XI), dont le génial moyen d'expression trouve toute sa mesure dans la représentation de certains rapports et mouvements complexes ( $\mathrm{pl}$. X/3). D'une cerlaine manière, on peut dire que l'ensemble le plus simple ( $\mathrm{pl}$. IX/2) se présente suivant un motif qui en détermine deux et qui est lui-même déterminé par deux autres. De là, on jugera de la richesse d'expression de ces figures, en considérant, par exemple, la progression du mouvement précisé dans le tableau du passage charretier septentrional d'Angkor Vat ( $\mathrm{pl}$. X/2).

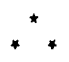

Si l'on songe que les références naturelles, le contexte humain et le cadre universel de toute expérience esthétique ont imposé des bases communes a tous les peuples, et que, de surcroît, les lois linéaires et géométriques de toute composition impliquent des limites et des rapports nécessairement communs à toute expression picturale, alors, l'exceptionnel parti que les Khmers ont tiré de ces données essentielles se dégage de son cadre particulier pour contribuer à rendre un des traits les plus remarquable du génie humain, celui de l'expression artistique. D'ailleurs, dès 1913, G. Ciœelès avait attiré l'attention sur l'intérêt que présentaient les piédroits d'Angkor Vat (1). Ces tableaux sont, en effet, avec ceux des autres monuments, la figuration la plus riche des ensembles ornementaux illimités d'Angkor. Et, au dela de leur expression propre dont le caractère iconographique n'est qu'un aspect particulier, se précisent les lois fondamentales qui réglèrent leur exécution, La nature essentielle de ces lois qui expriment, dans tous les cas, divers aspects d'une dualité constitutive, nous semblent déterminer le fondement véritable de la forme la plus discrète mais non la moins profoncle de l'Art : l'Ornementation.

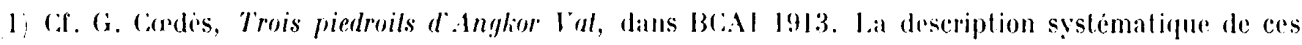

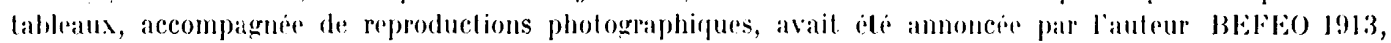

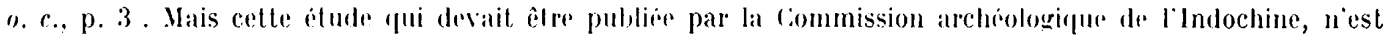
jamais parue.

On a employe, pour les monuments du style du Bayon, la terminologie pricisce par Pii. Stern, Les monuments lihmers du style du Bayon et Jayawarman VII, Paris 196.); Les lellures alphabctiques utilisées pour Ta Prohm renvoient au plan de L. de Lajonquiere, Inventaire descriptif des .Monuments du Cambodge, 1. III, l'aris 1911, fig. 61; la numerolation des differentes parlies du Bayon est celle de H. Parmentier, BEFEO 19:7, pl. V. cf. également, J. Dumarcay, Le Bayon, Histoire archilecturale du lemple, Paris 1967). 


\section{TABILE IDES MATIËRES}

1. Les motifs : les molifs floraux de face; les molifs floraux de profil; les molifs floraux ciliés; les motifs circulaires; les molifs quadratiques. 2. Les structures : les semis; les ramages; les réseaux..................

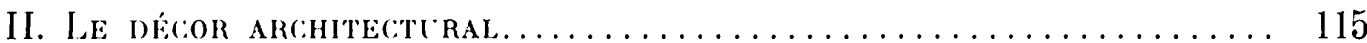

1. Les stores des fausses fenêtres. 2. Les façades. 3. Les demi-galeries : l'inlrados des demi-voûtes; la face inlérieure des architraves; les demi-fronlons. 4. Les tableaux de baies : le monde végétal; le monde animal; le monde humain...

I)euxieme parlie

L'ORNEMENTATION.

1. Les figures à carreaux. 2. Les figures à carreaux alternés. 3. Les figures à médaillons circulaires. 4. Les figures à ramages................... 


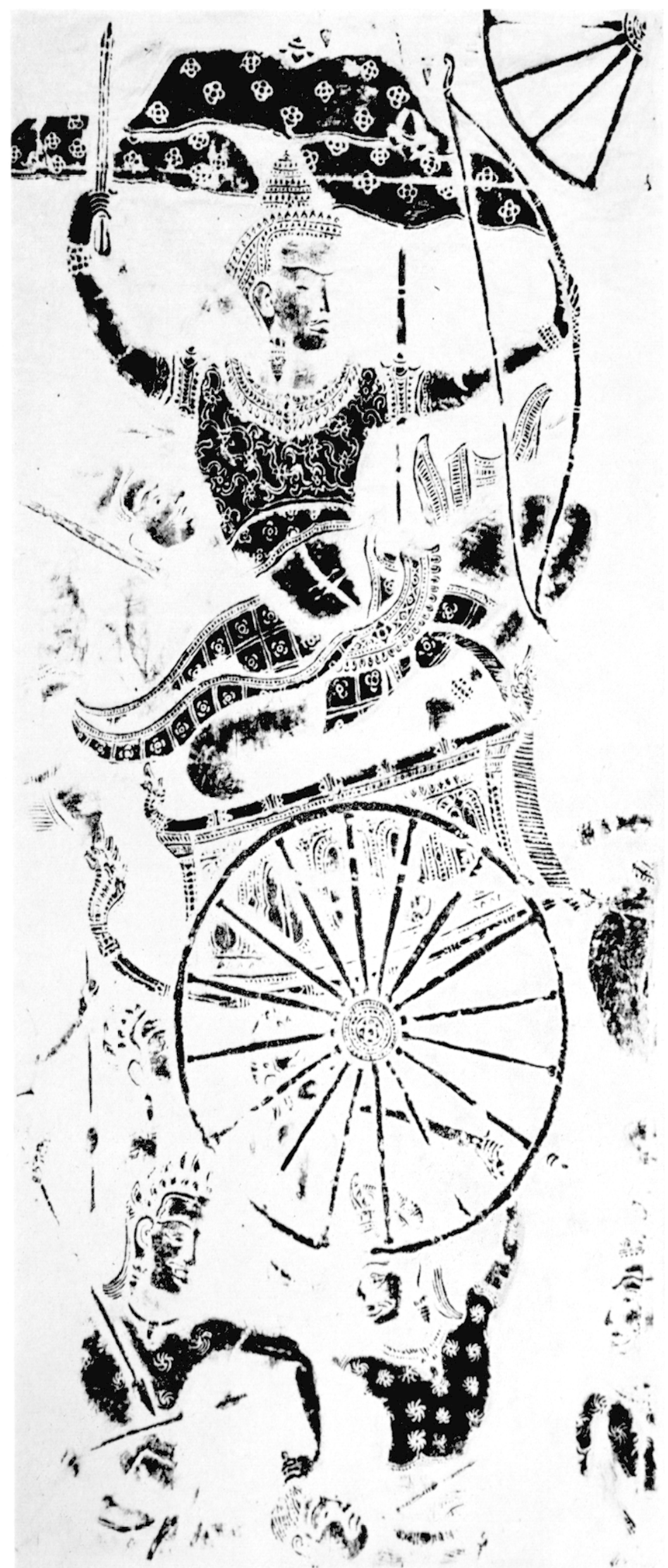


Planche II

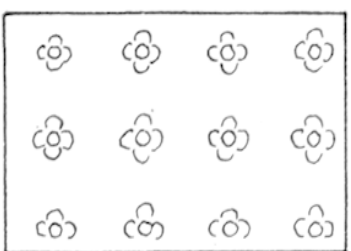

Fig. 1

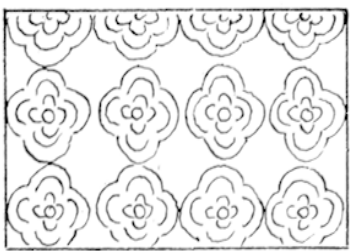

Fig. 5

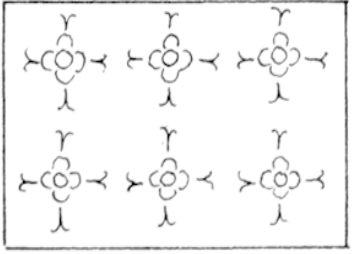

Fig. 9

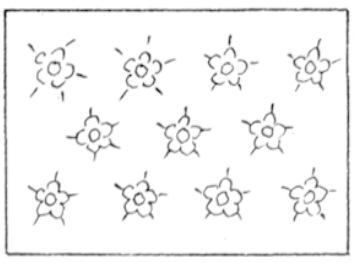

Fig. 13

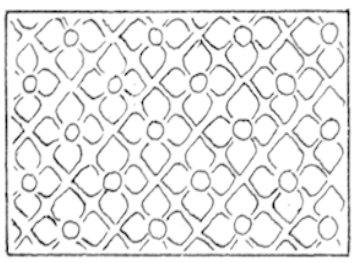

Fig. 17

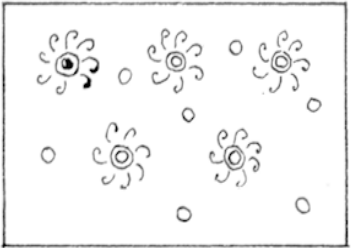

Fig. 21

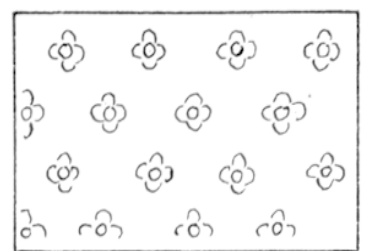

Fig. 2

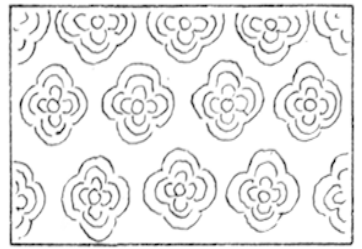

Fig. 6
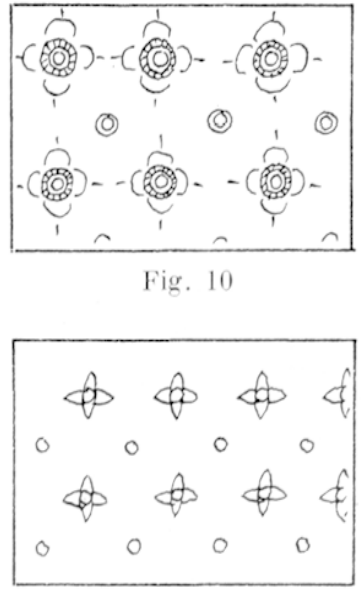

Fig. 14

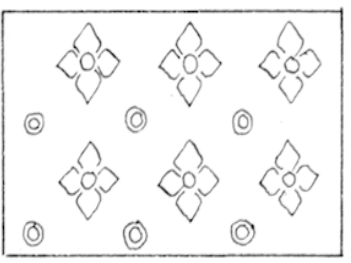

Fig. 18

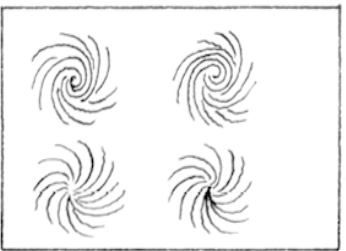

Fig. 22

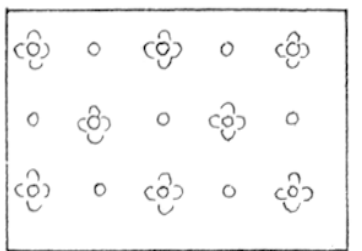

Fig. 3

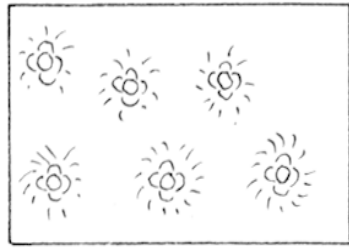

Fig. 7

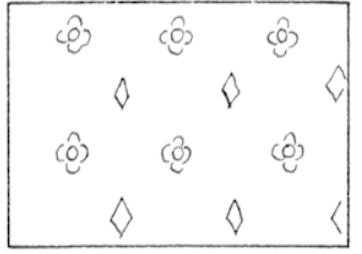

Fig. 11

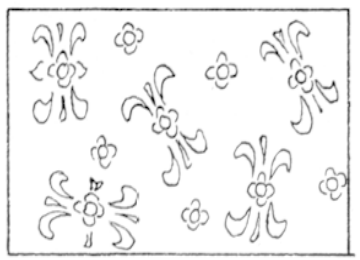

Fig. 15

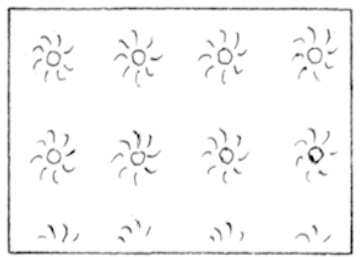

Fig. 19

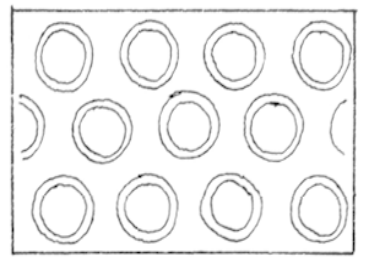

Fig. 23

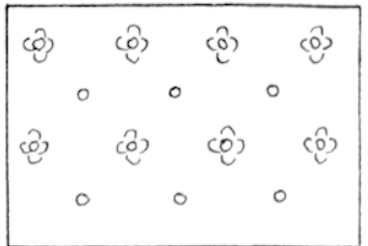

Fig. 4

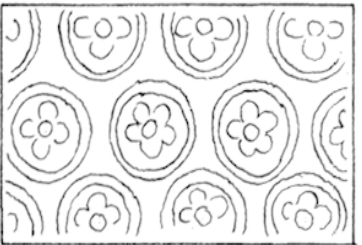

Fig. 8

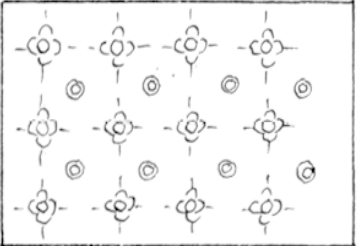

Fig. 12

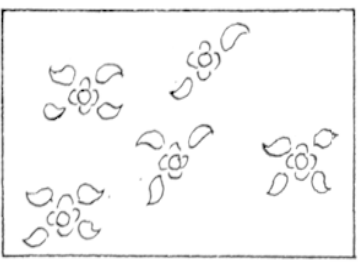

Fig. 16

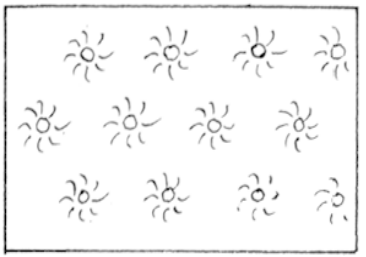

Fig. 20

(-) (0) (0) (0) (0) (O) (a) (0) (C) (0) (O) (O) 0

(0) (0) (0) (0)

Fig. 24

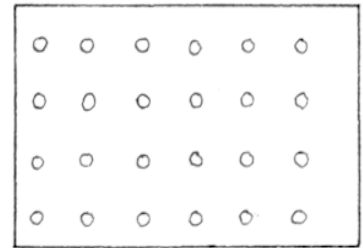

Fig. 25

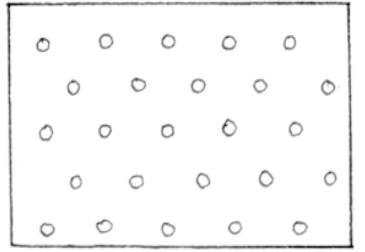

Fig. 26

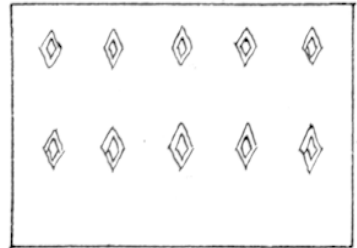

Fig. 27

Ces planches offrent des exemples-types de chacun des aspects auxquels lornementation des tissus figures sur les bas-reliefs a donné lieu. J.es dessins pl. II et Vi sont schematiques sauf pour quelques variantes de motifs qu'il convenait d'illustrer) et les estampages pl. III at IV) ont été pris là ou les meilleures conditions se rencontraient netteté du dessin, qualité de la pierre', c'est-à-dire presque toujours à Angkor Vat. Aussi, en raison de ce choix arbitraire, la situation de chacune de ces figures ne sera pas donnec. 
Planche III
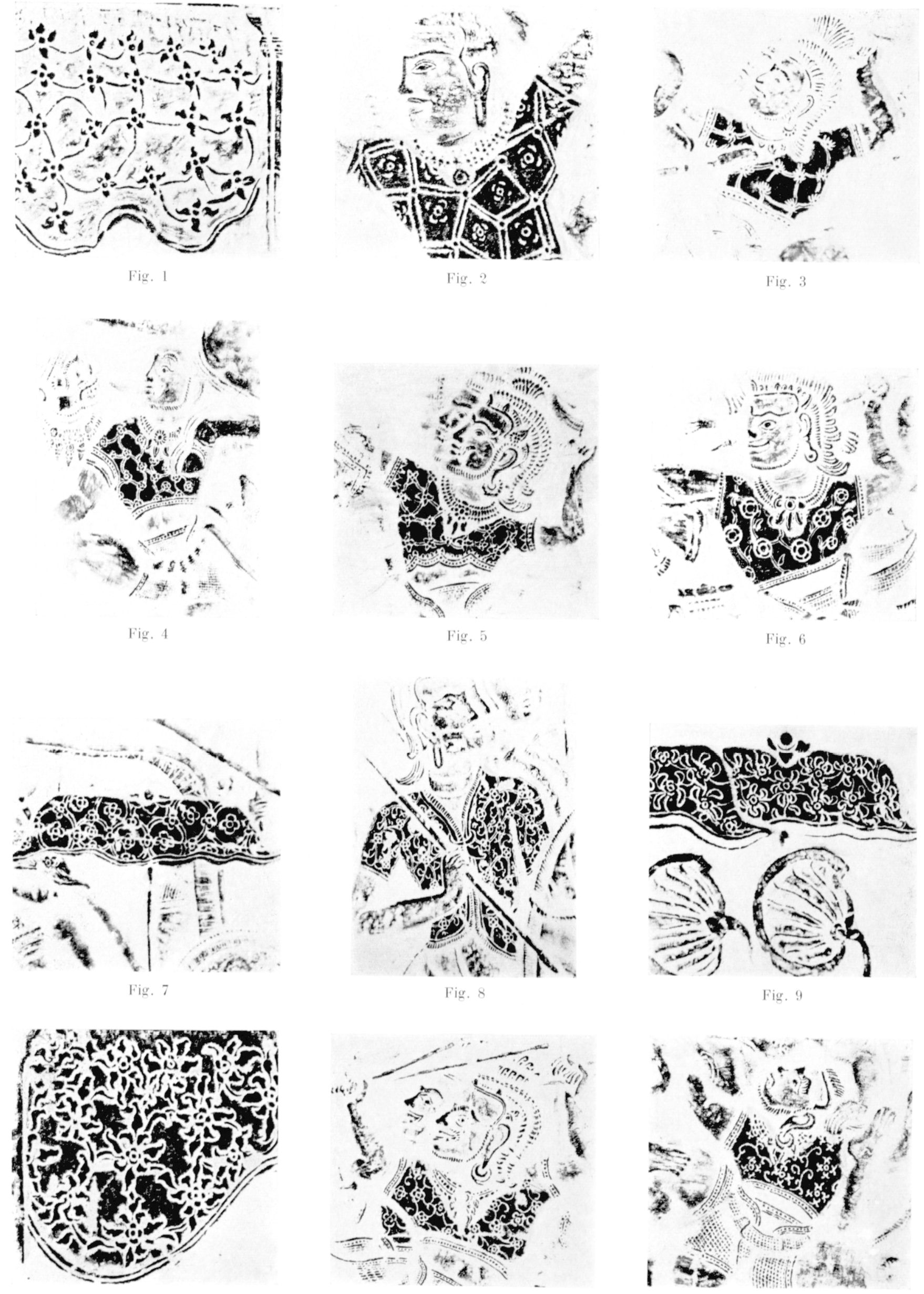

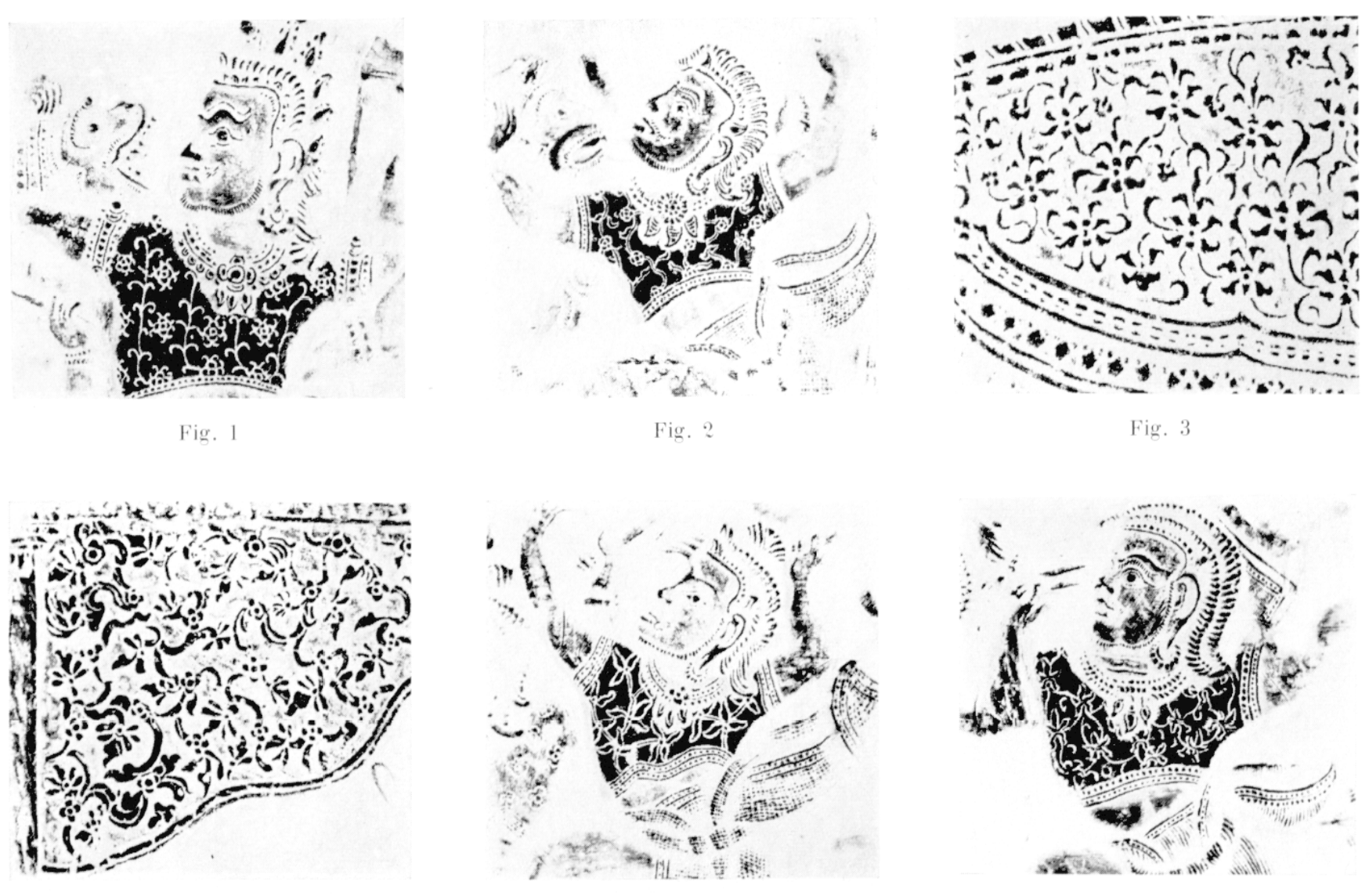

Fig. 4
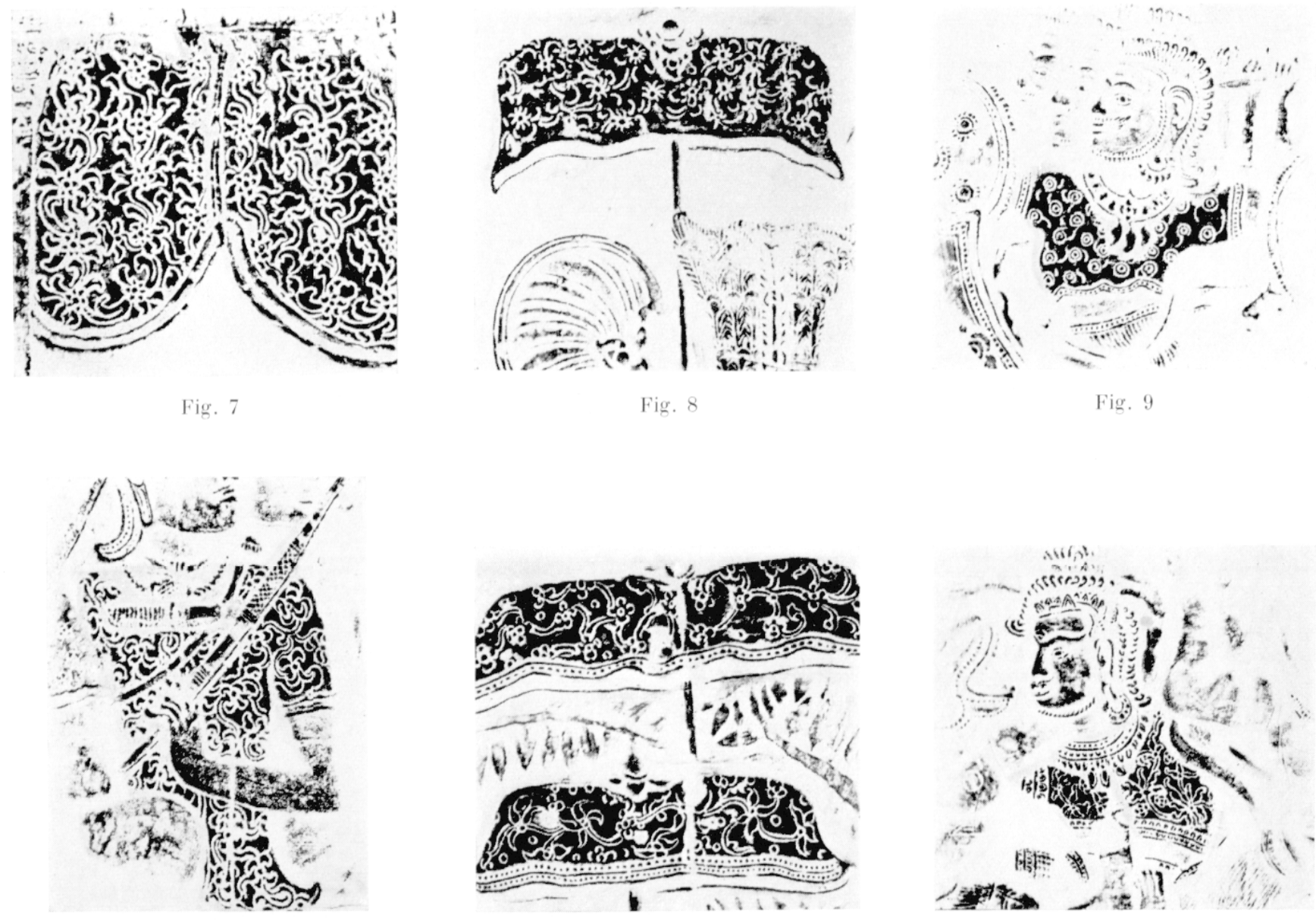


\section{Plaxiche $V$}

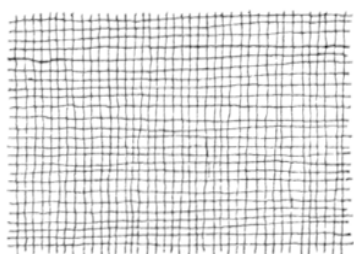

Fig. 1

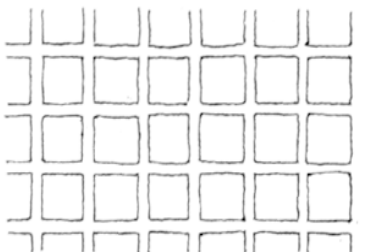

Fig. 5

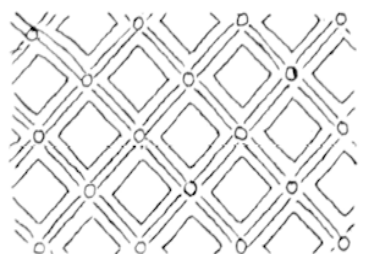

Fig. 9

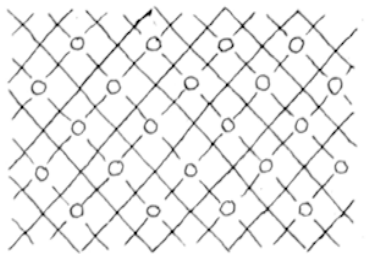

Fig. 13

\begin{tabular}{|c|c|c|c|c|}
\hline & 8 & 80 & & (क) \\
\hline శ్ర & (8) & 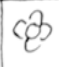 & 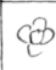 & $c 8$ \\
\hline ces & $(\beta)$ & $c 0$ & 83 & $(\theta)$ \\
\hline
\end{tabular}

Fig. 17

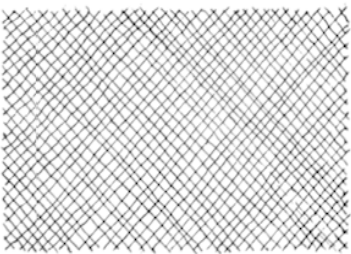

Fig, 2

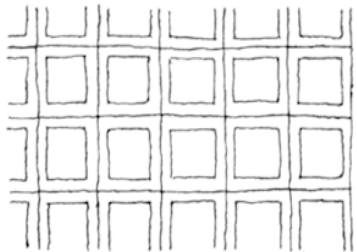

Fig. 6

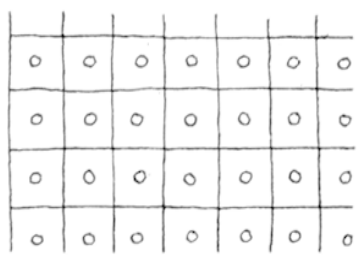

Fig. 10

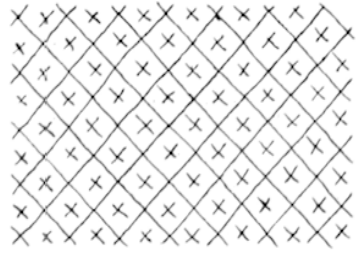

Fig. 14

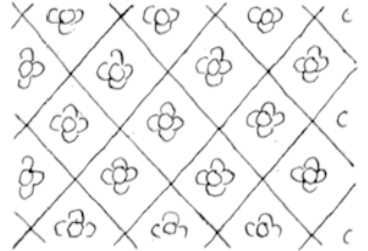

Fig. 18

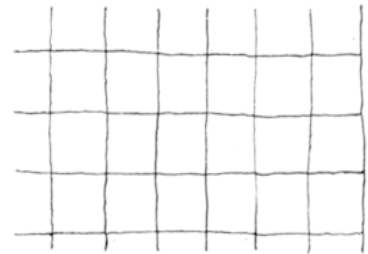

Fig. 3

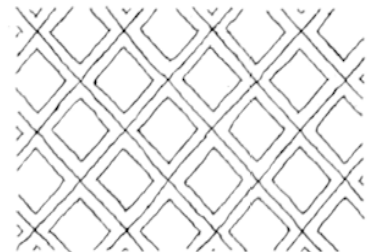

Fig. 7

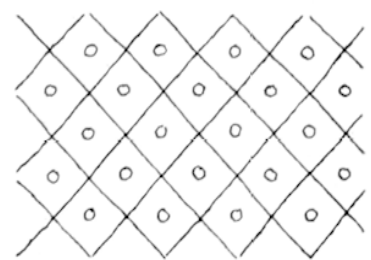

Fig. 11

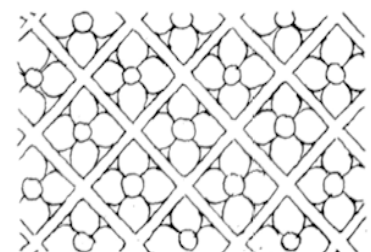

Fig. 15

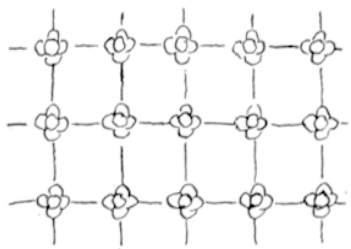

Fig. 19

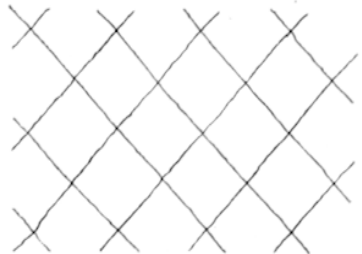

Fig, 4

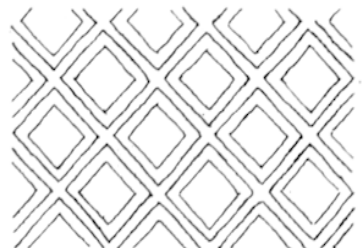

Fig. 8

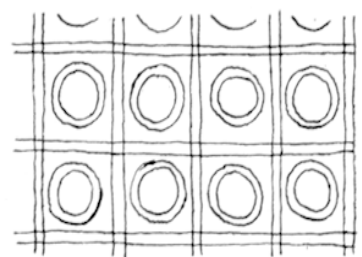

Fig. 12

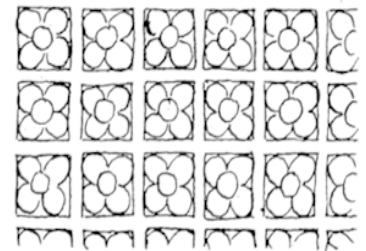

Fig. 16

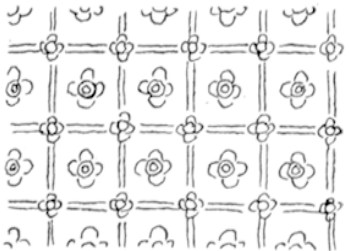

Fig. 20

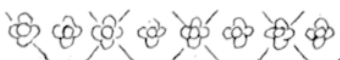

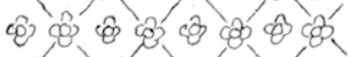
कर कि कि की

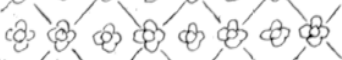

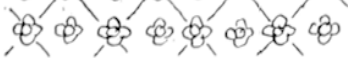

Fig. 21

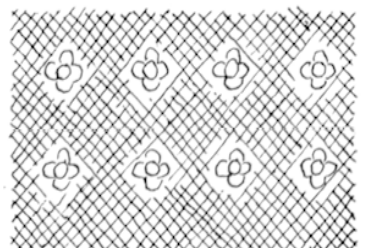

Fig. 2\%

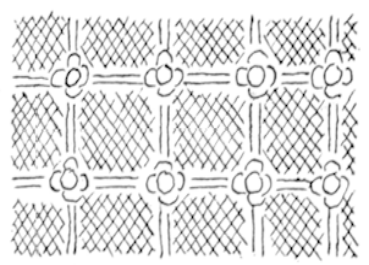

Fig. 23

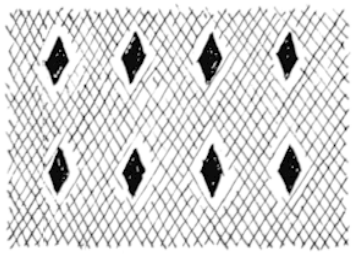

Fig. 24

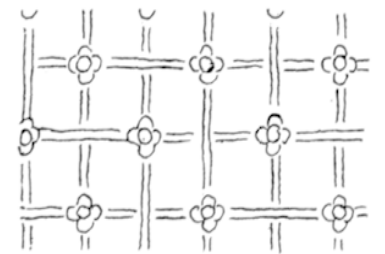

Fig, 25 


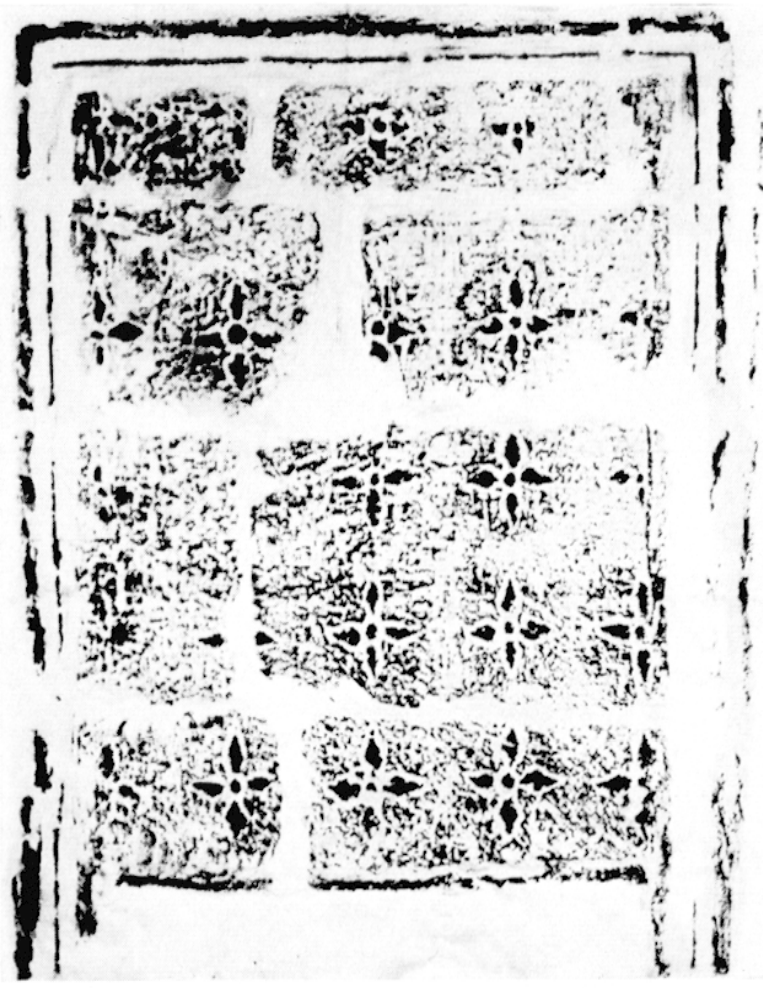

Fig. 1. - Banteay Kdei, enceinte de domaine, gopura list, avant-corps sud, facade lisl.

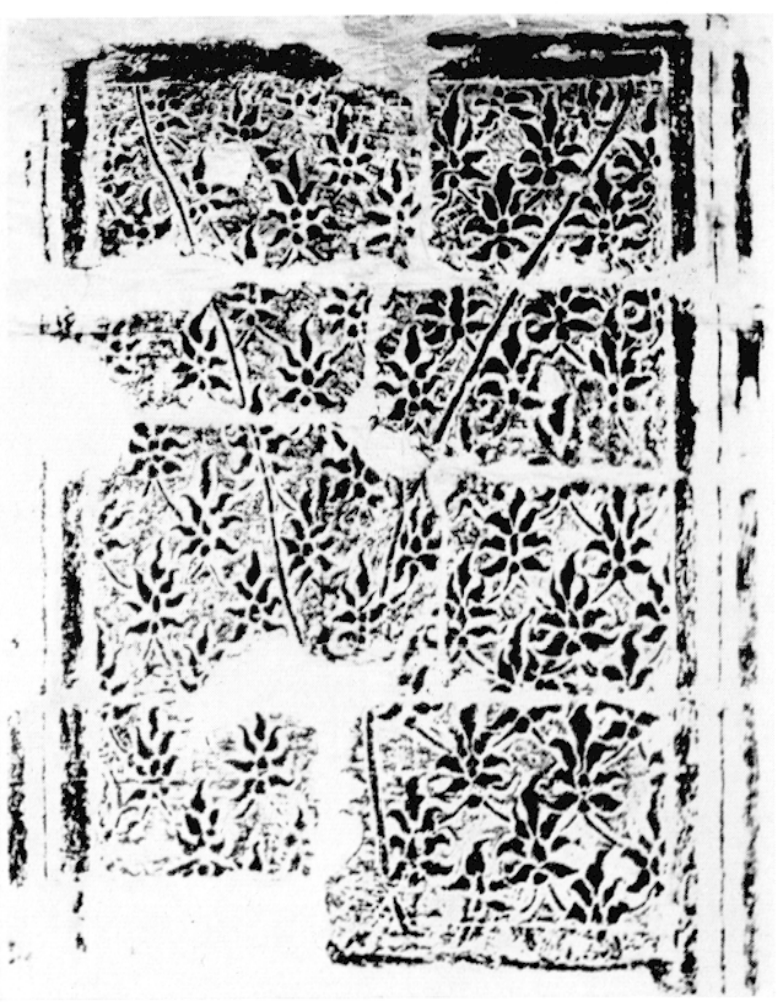

Fig. 3. -- Banteay Kdei, salerie enceinte intermédiaire, cóte Est, gopura Est, aile Nord, ? paroi extérieure Est.

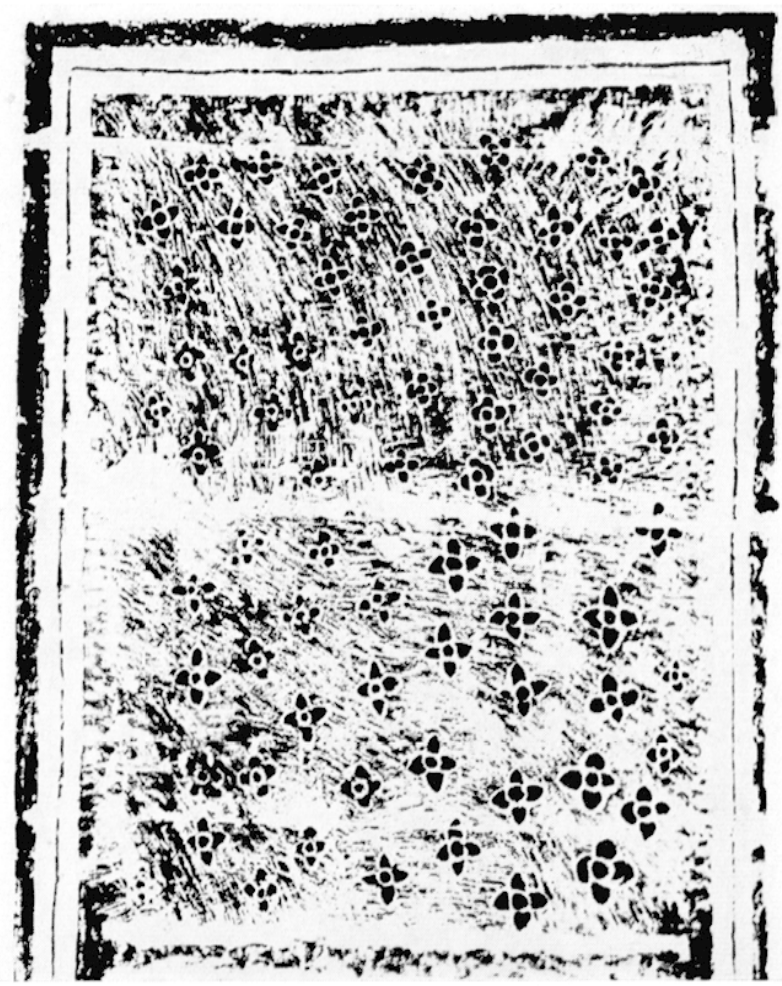

Fig. 2. ... Ta Prohm, intérieur veranda de passage E, paroi sud de la chambre D.

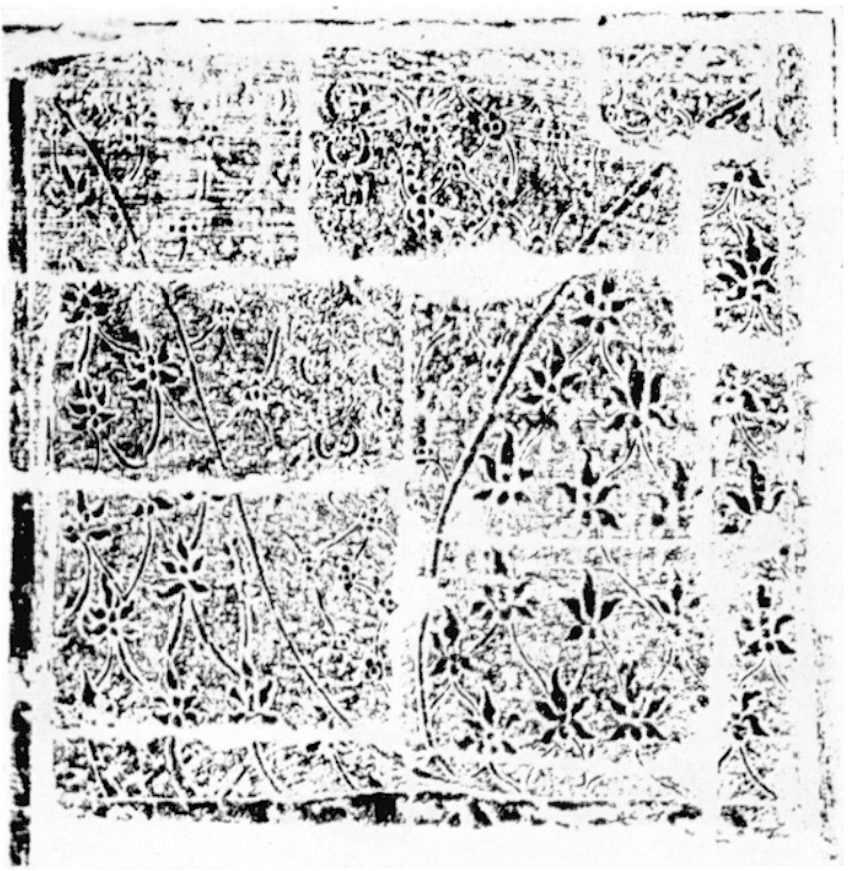

Fig. 4. - Banteay Kolei, galerie enceinte intermédiaire, còté Ouest, gopura Ouest, avant-corps Nord, paroi kst, façade exterieure. 


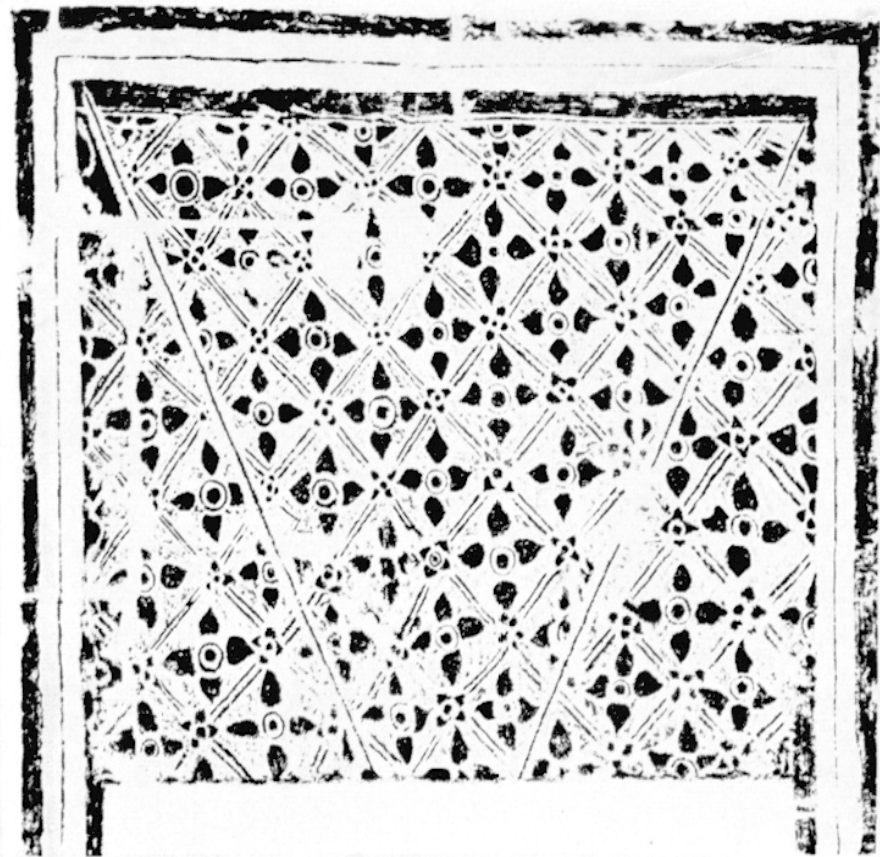

Fig. 1. - Bayon, tour sanchaare 3, avant-corps exterieur, paroi Est

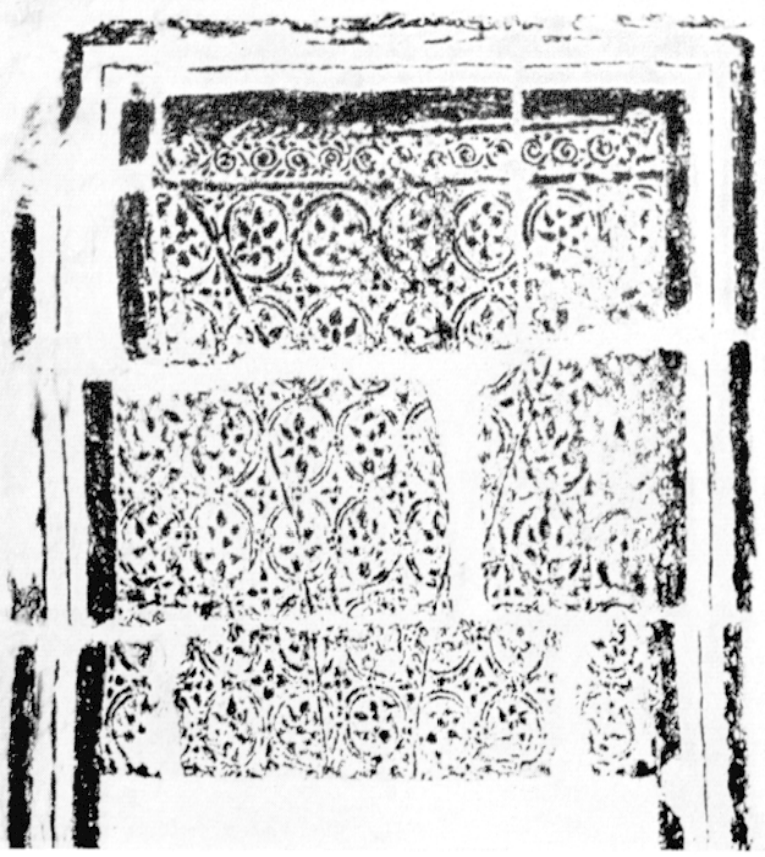

Fig. 3. -... Banteay Kdei, galerie enceinte interieure, toursanctuaire d'angle Nord-Est, galerie de passage list, paroi Sud, fausse fenêtre Est.

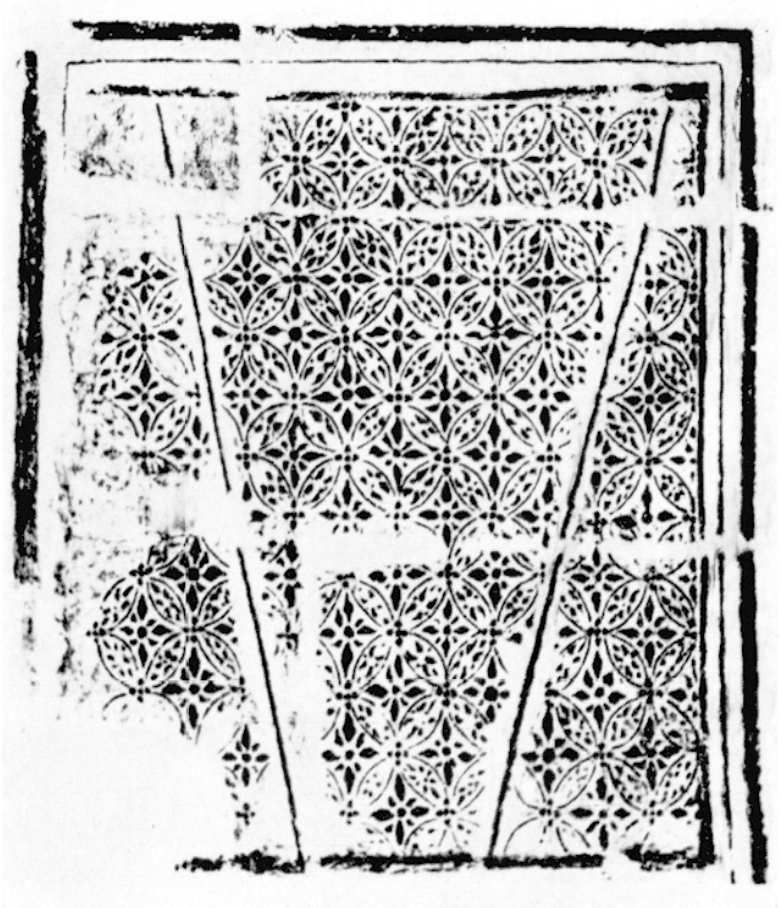

Fig. :. Bayon, idifice 15, avant-corps list, fausse: fenêtre sud.

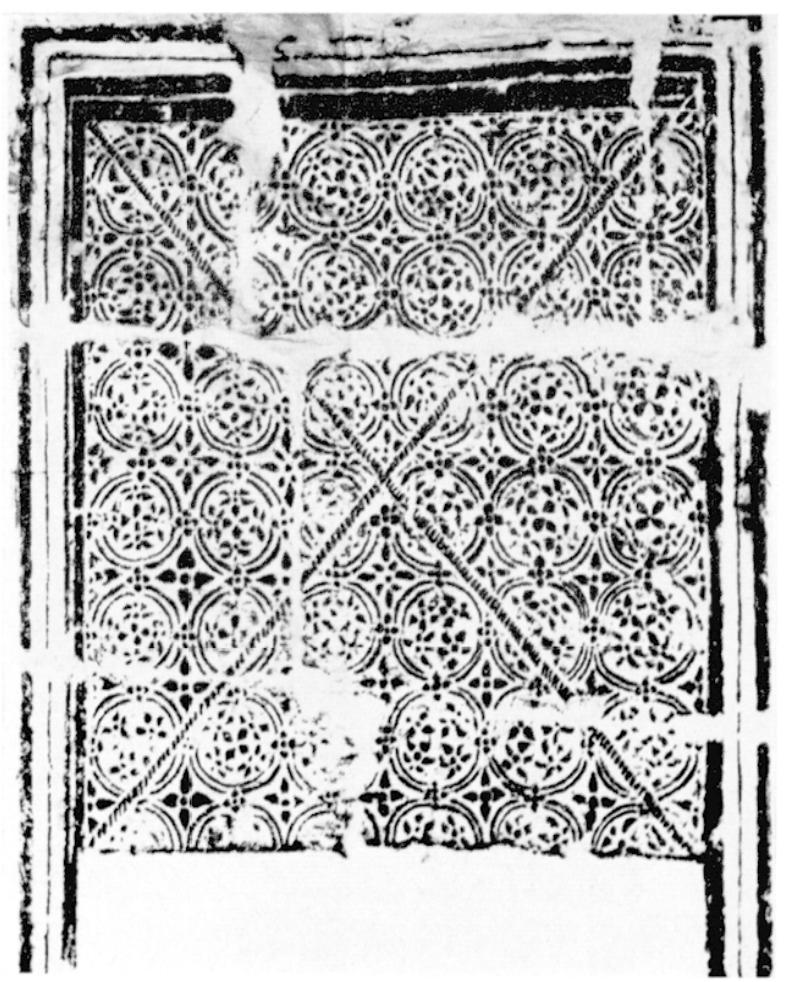

Fig. 1. Bayon, four-sanctuaire 13, avant-corps sud, fansse fonètriz Ouest. 


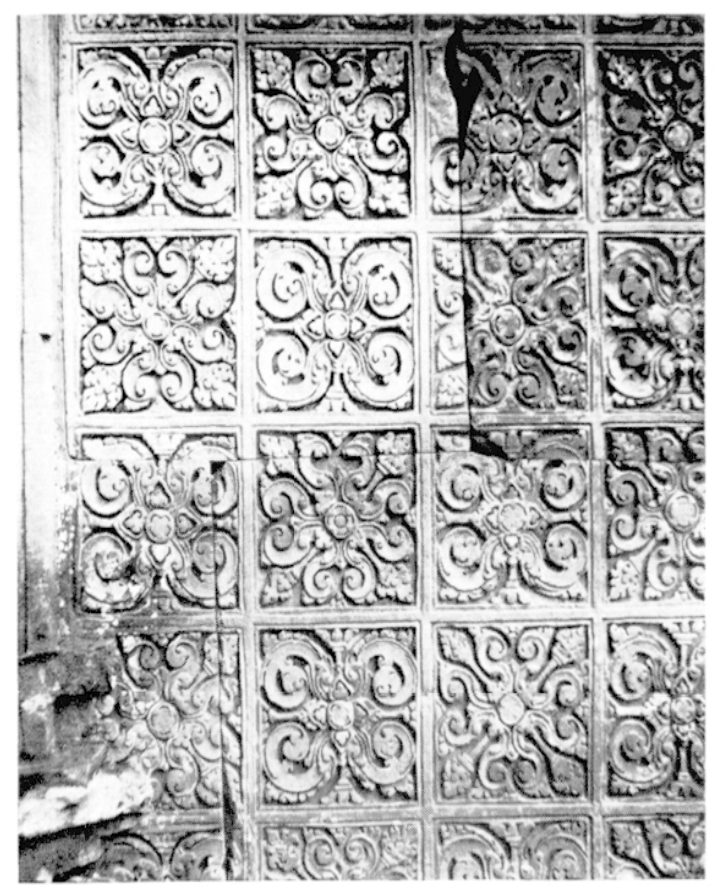

Fig. I. Banleay Kidei, sancluaire central, mandapa, farade Norrl.

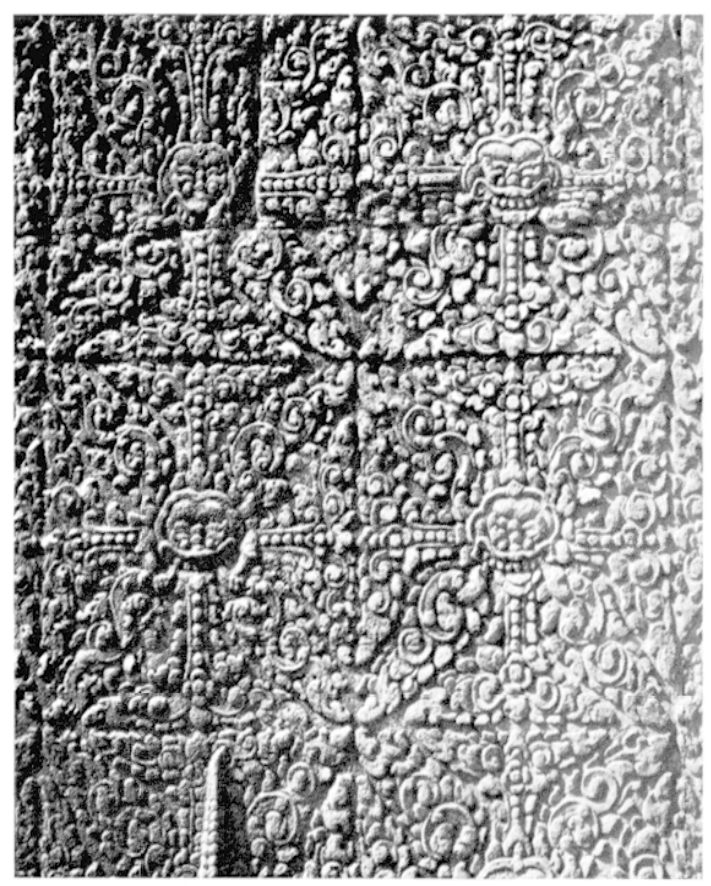

Figr. : - Angkor Vit, t" mecinte, critr Onest, gopuri (ourst, faciale list.

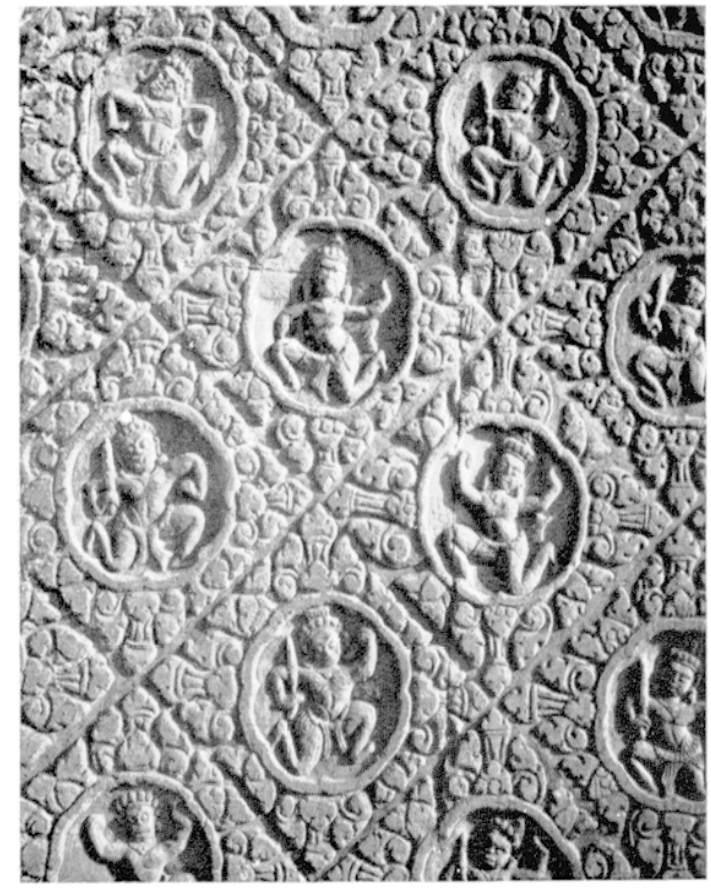

Jigr. 3. Angkor Viat, f" enceinte, coli (Ouest, gopura Ouest, passage central, ler faux-itage, angle sud-list.

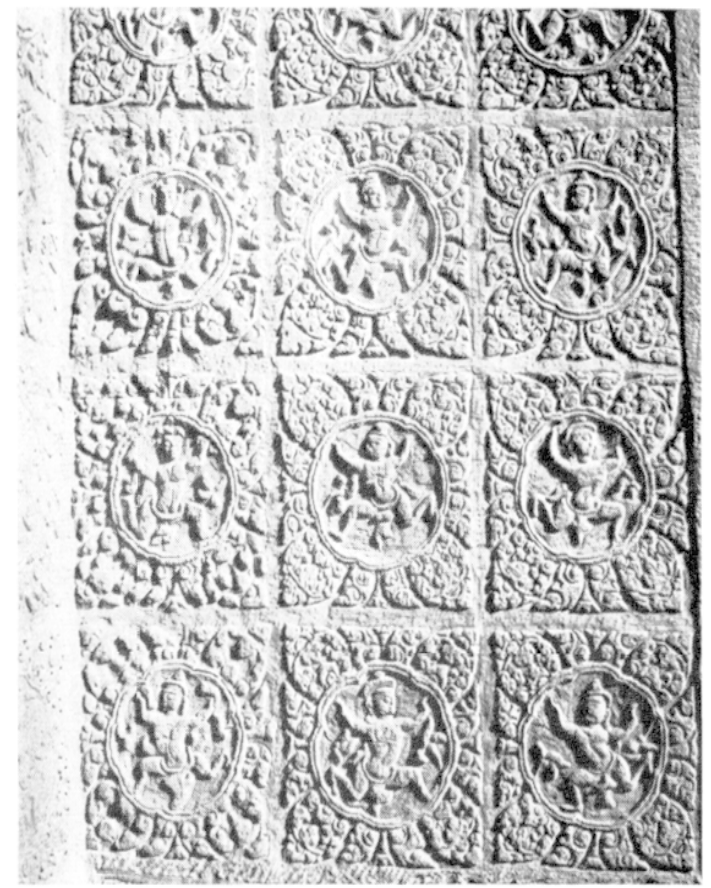

Fïgr. 1. - Angkor Vat, fre enceinte, paivillon d'angle cord-fuest, façade exterieure, parement xord. 


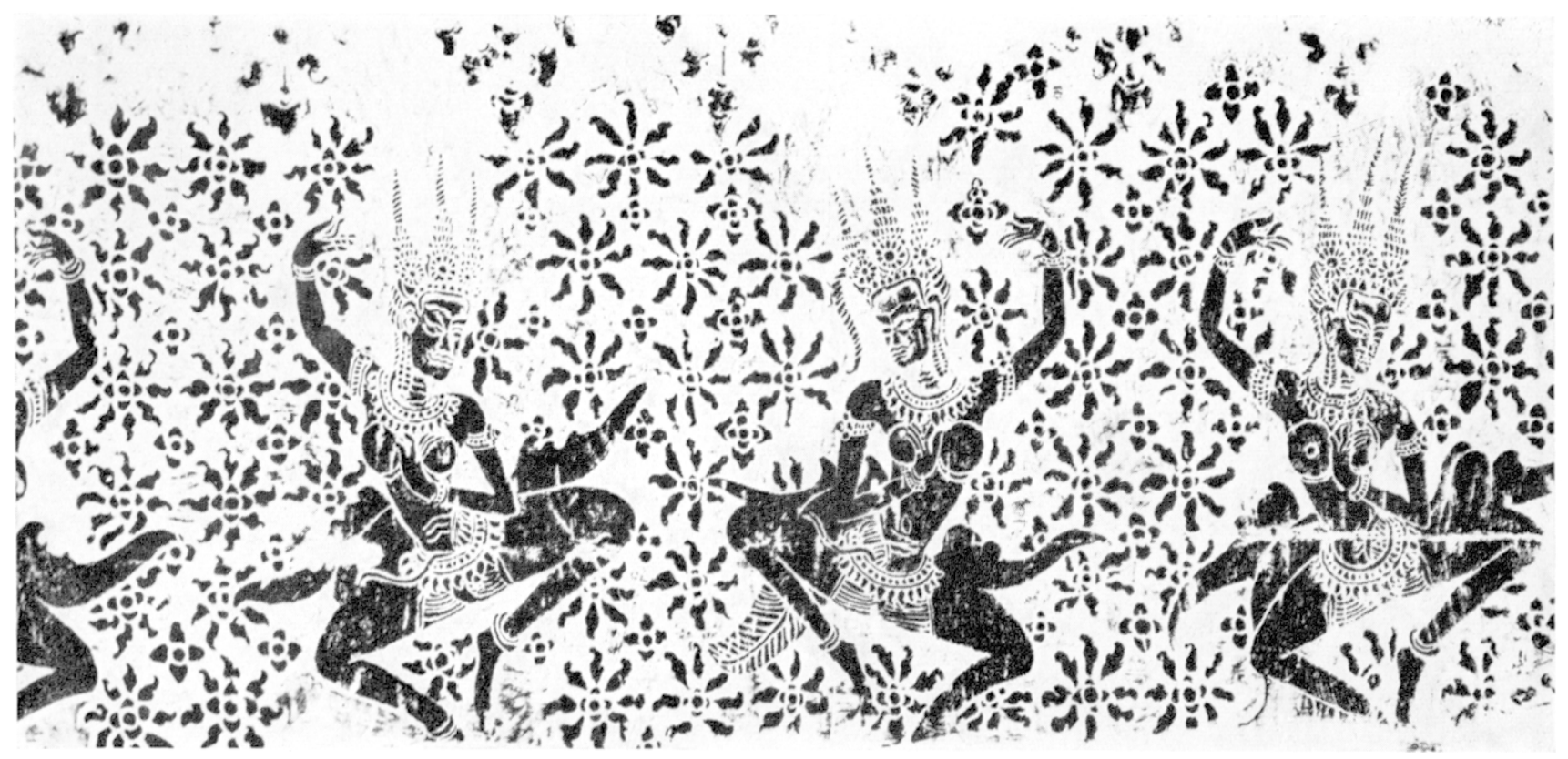

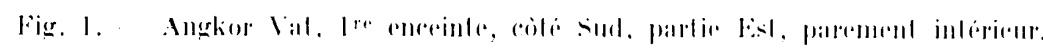

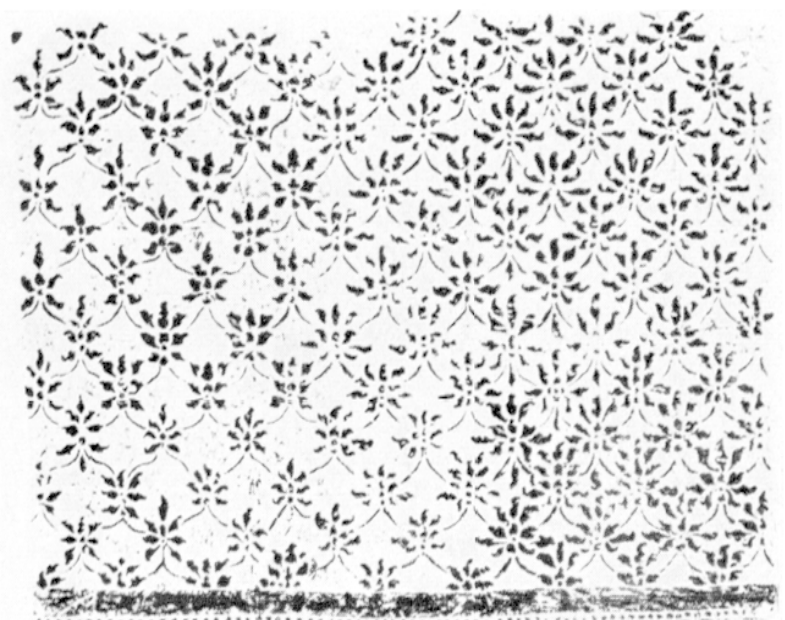

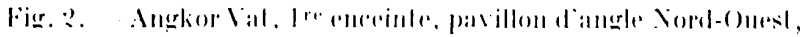

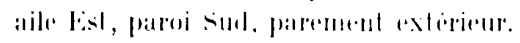

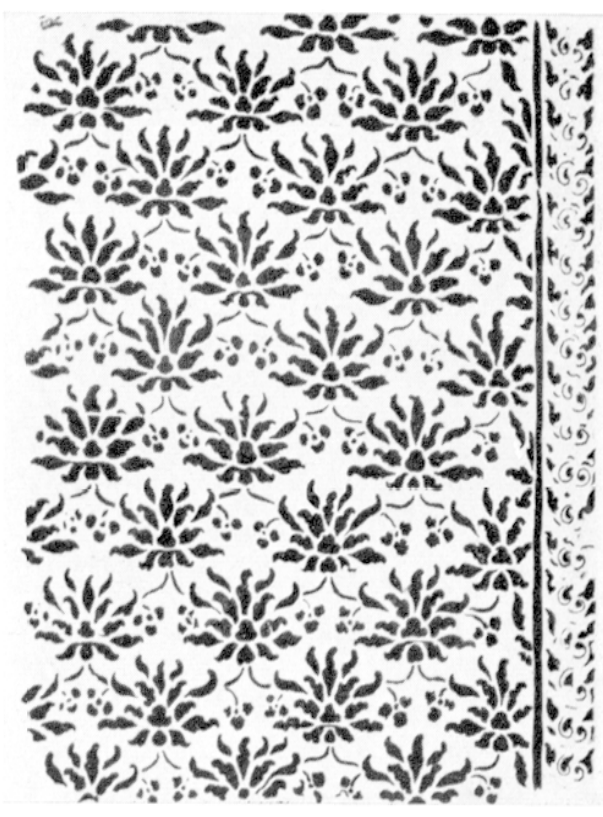

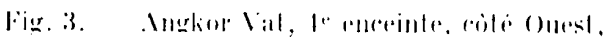

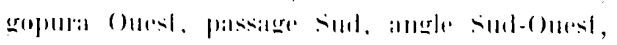

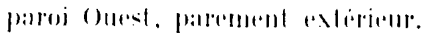

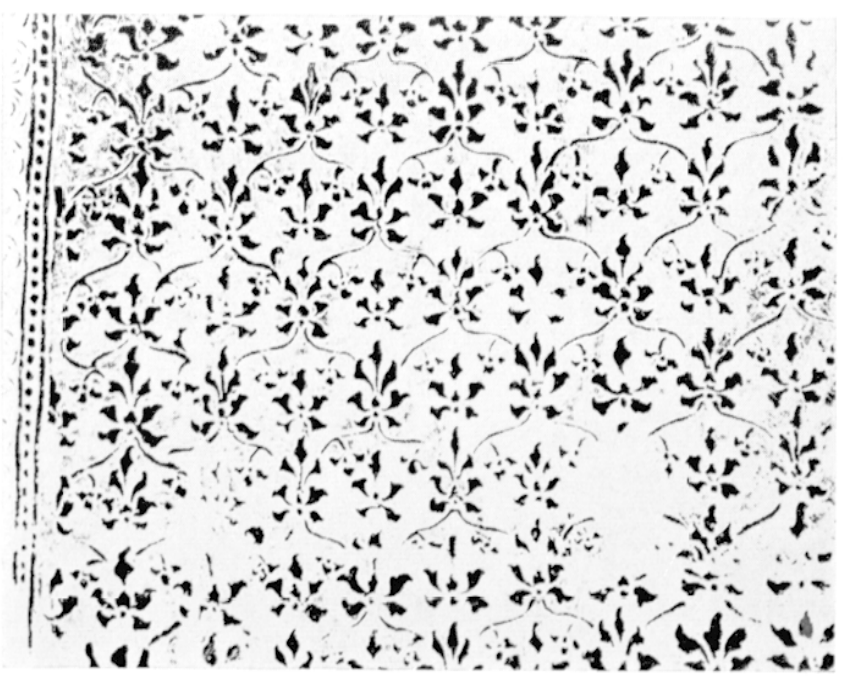

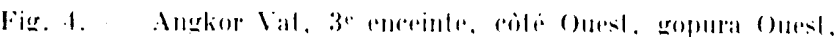




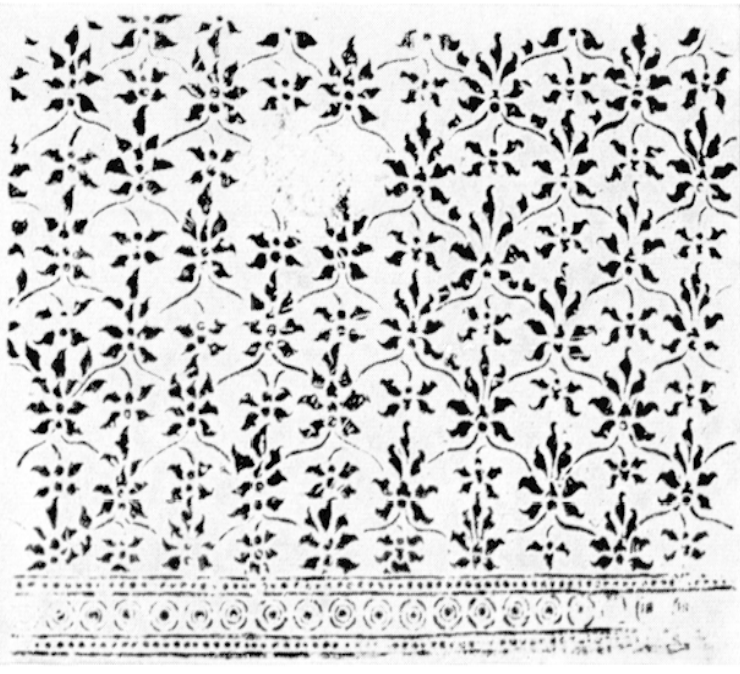

Fïr. 1. Angkor Vat, sancluaire central, porche Sud, paroi Ouesi, parement extiriente.

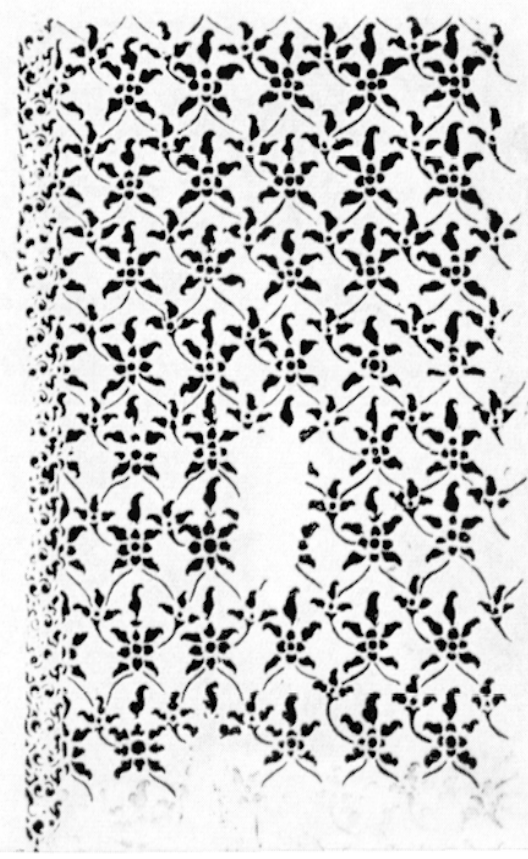

Figr. :. - Angkor Vat, fe rnceinte, cile Ouest, passinge charretier Nord, avantcorps sud, angle sud-()uest, parroi sumb, parement axlerientur.

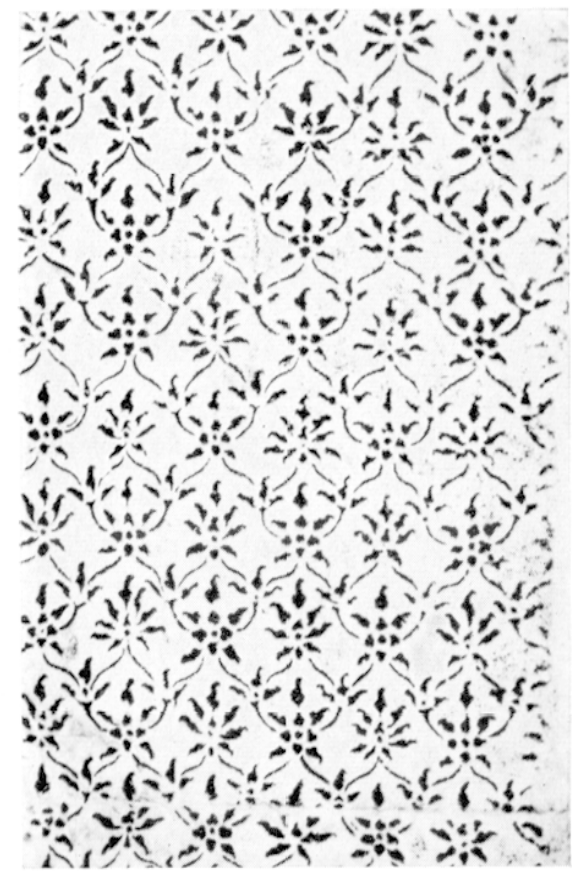

Figr. 3. -... Angkor lat, f"enceinte, còlé Oursi, gopura Ouest, passage Vord, avantcorps Kord, angle Nord-(Ouest, paroi Nord, parement exterieur.

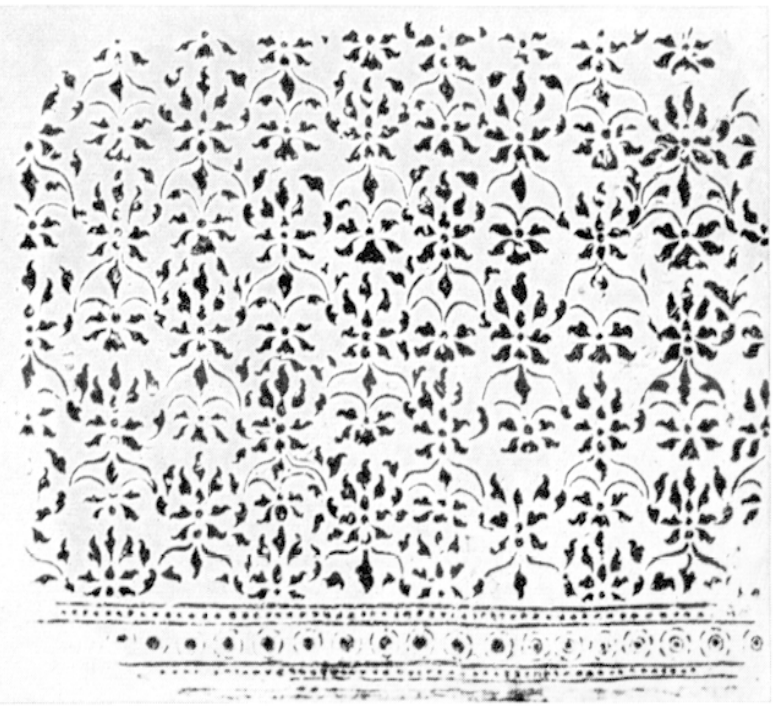

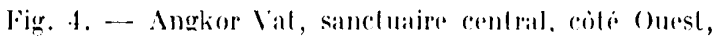
porche ounst, paroi sud, parement exterieur. 


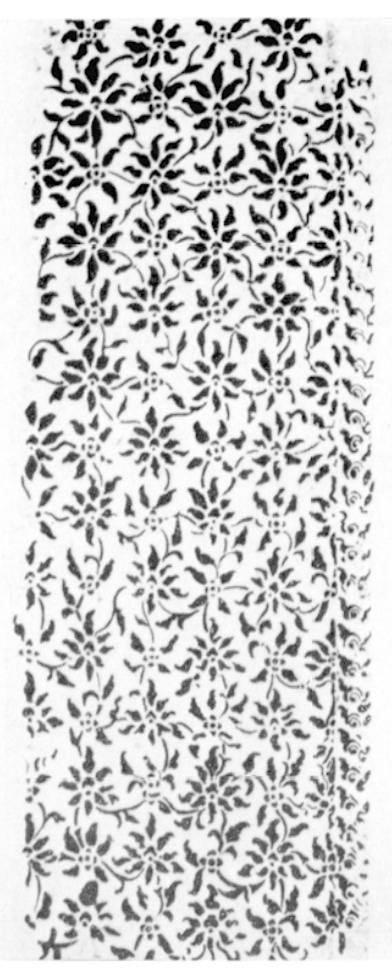

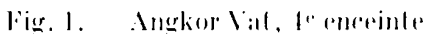

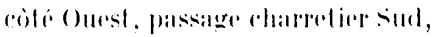
avant-corpse Nord, angle NordOuest, paroi Vord, parement rxlirisur.

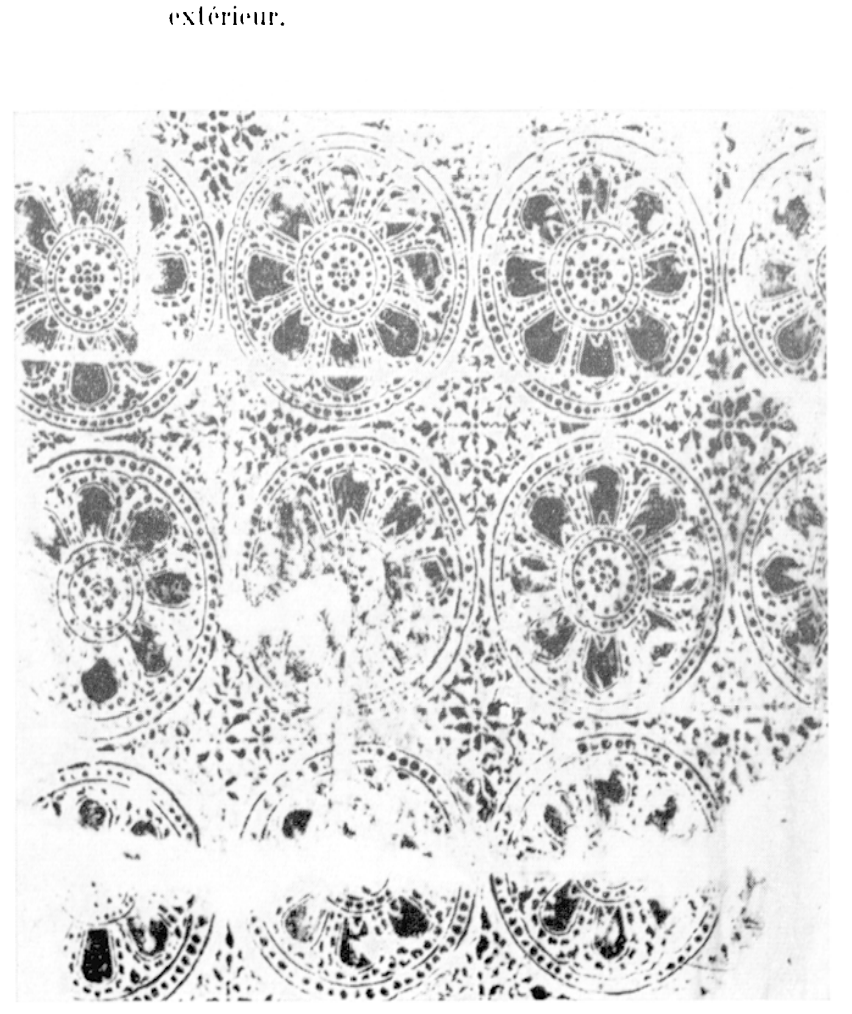

Fig. 3. - Angkor Vial, lre enceinte, colt Ouest,

corps de galterie Nord, demi-galerie, intrados de la demi-roùte.

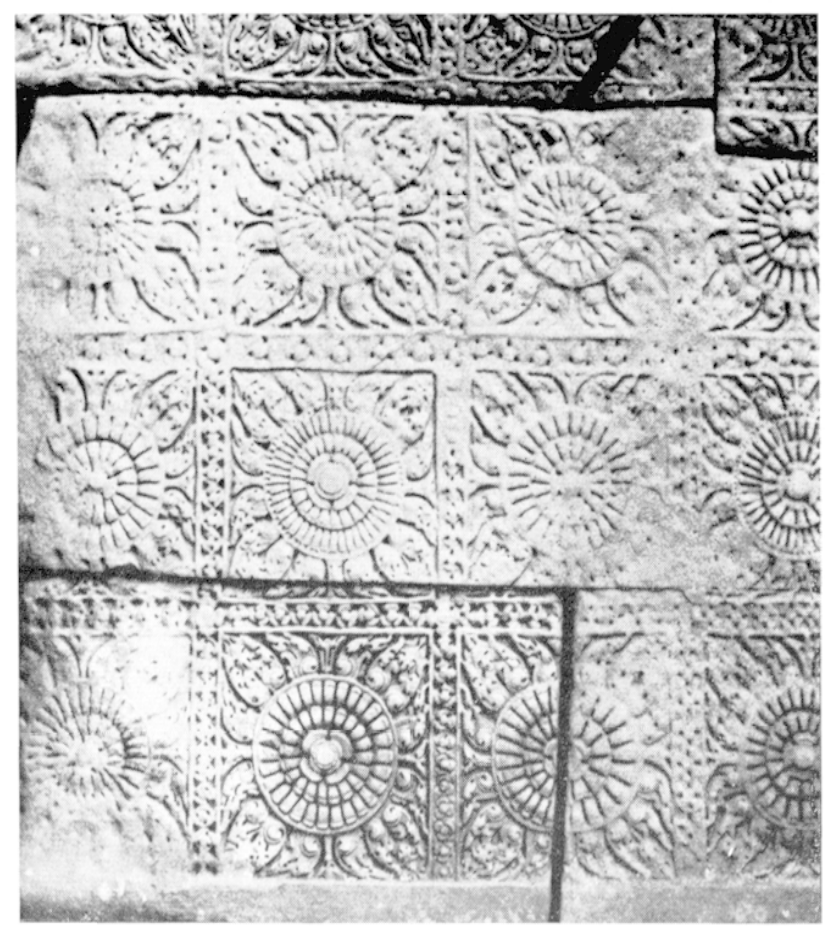

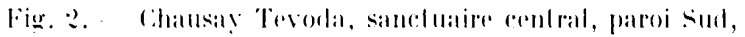
p:armentul exterient.

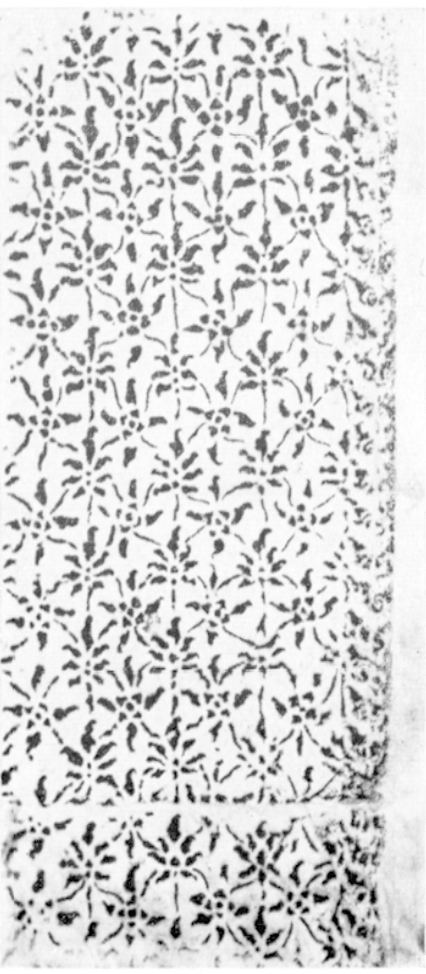

lïg. 4. Angkor Vial, t" encerinte, cita (Ouest, gopura (ourst, passagre Yord, aile Yord, paroi Ourst. ressaut de farade, parrment Nord. 


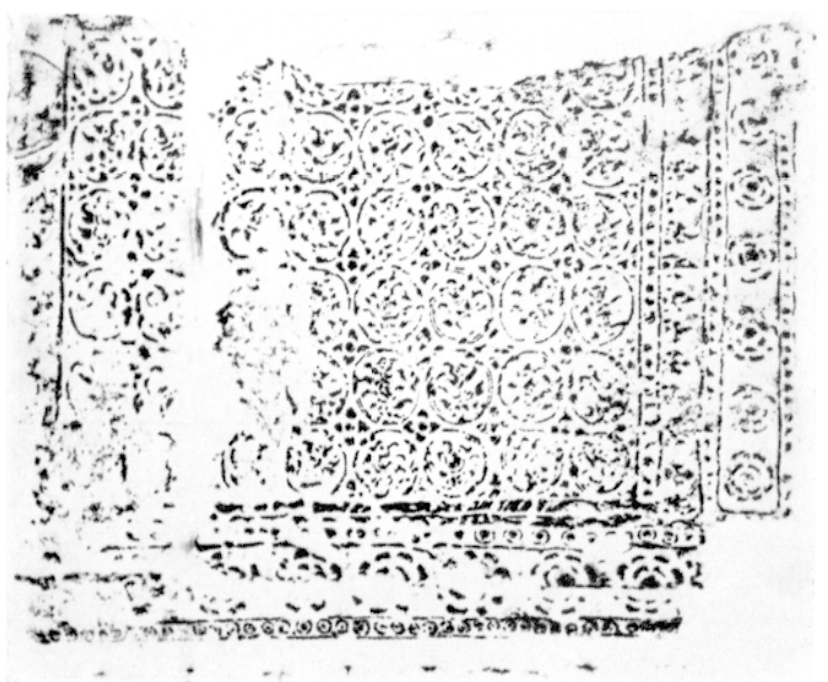

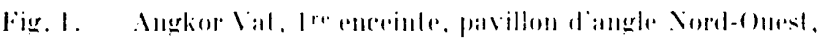

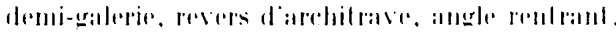

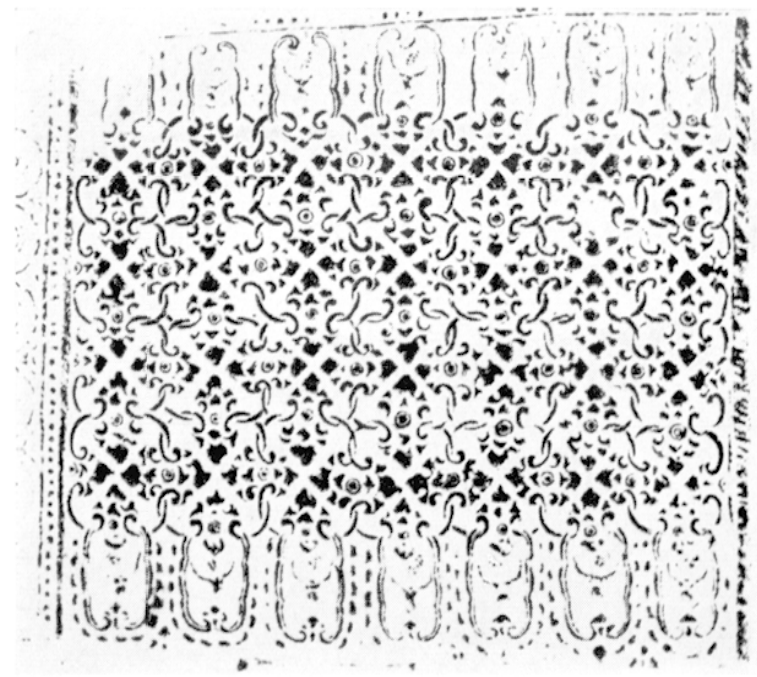

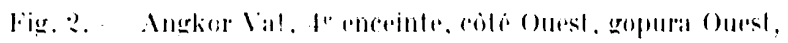

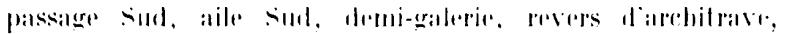
angle renlranl.

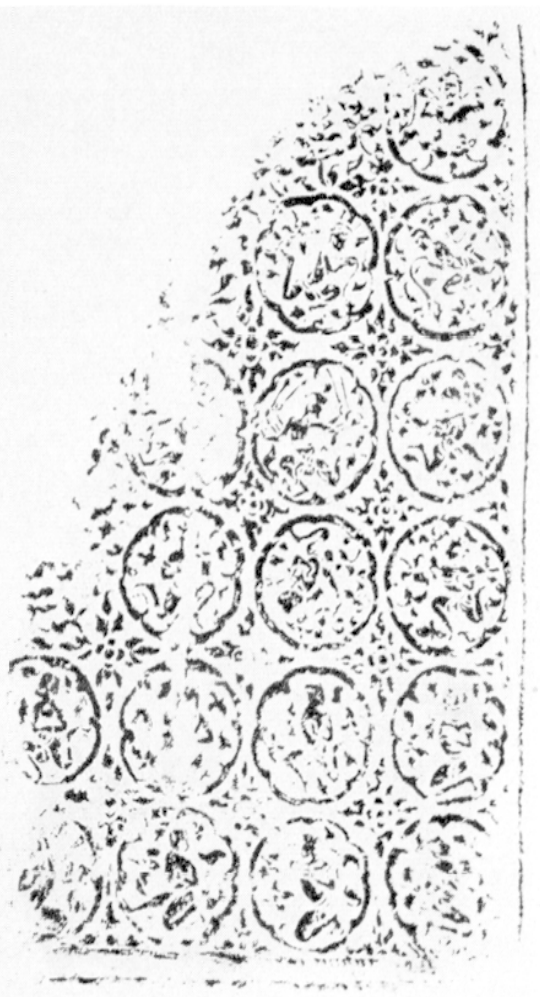

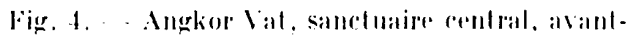
partement exterienur. corps ourest ate Nord, demi-galerie, demi-fromlon,

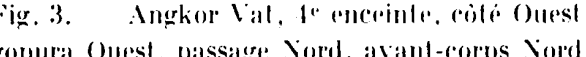
demi-galerie, demi-fronlon, parement exterienr.

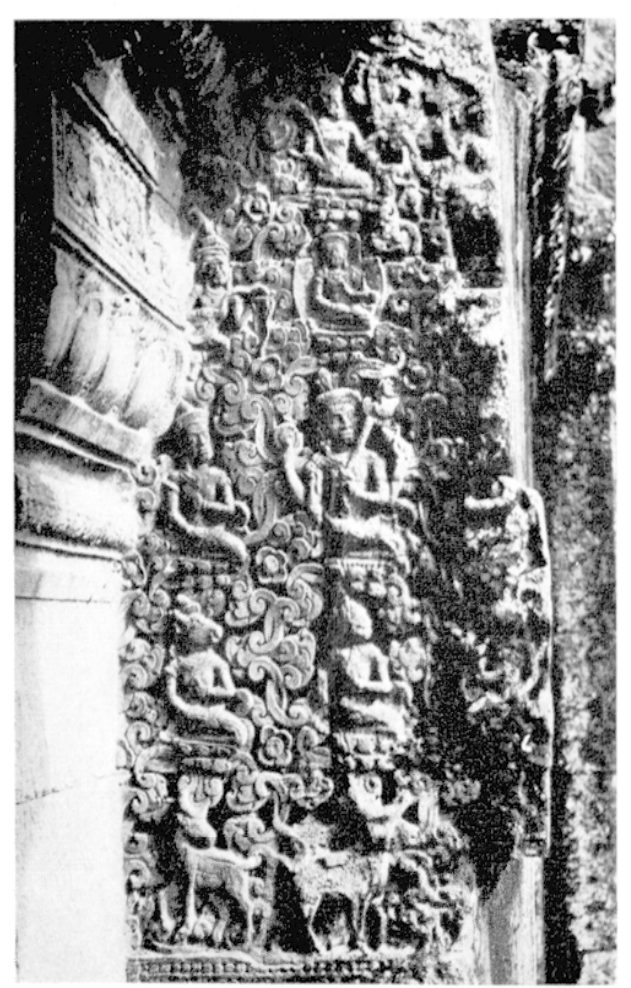

Fig. 3. Angkor Val, fe anceinle, cote ouest, 


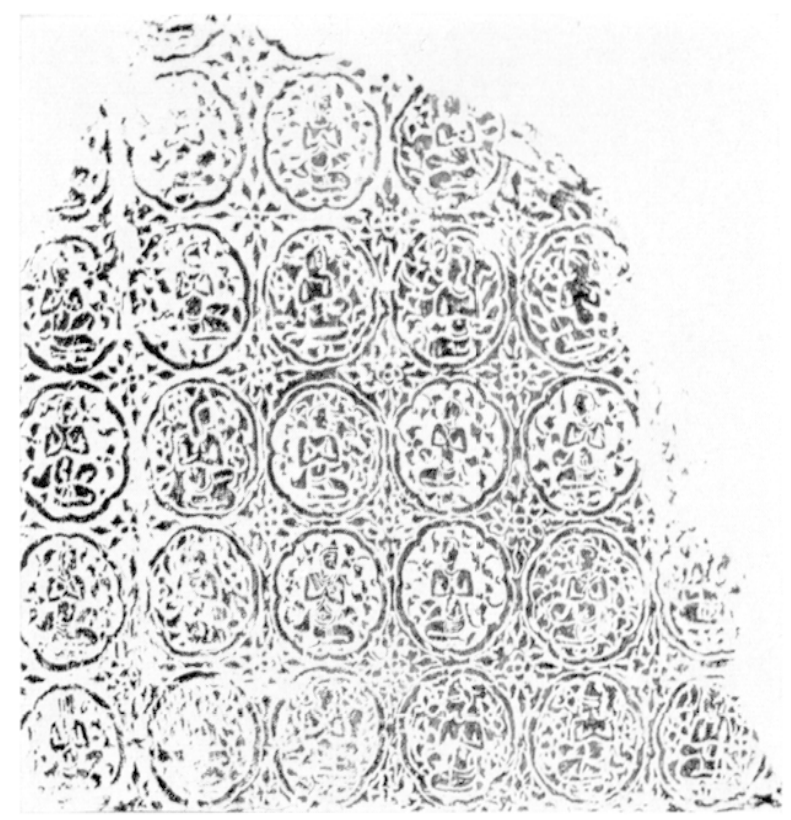

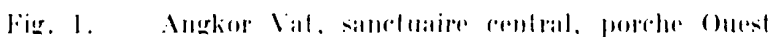

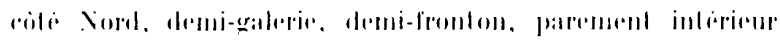

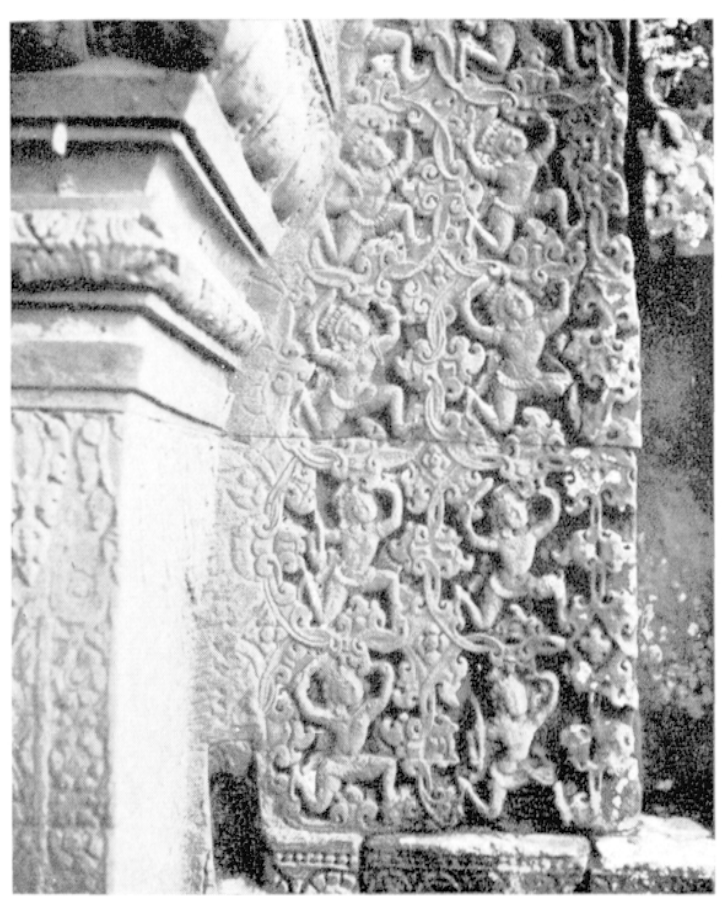

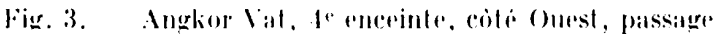
charretier sind, avant enps Nord, demi-galerie, demifronlon. parement exterient.

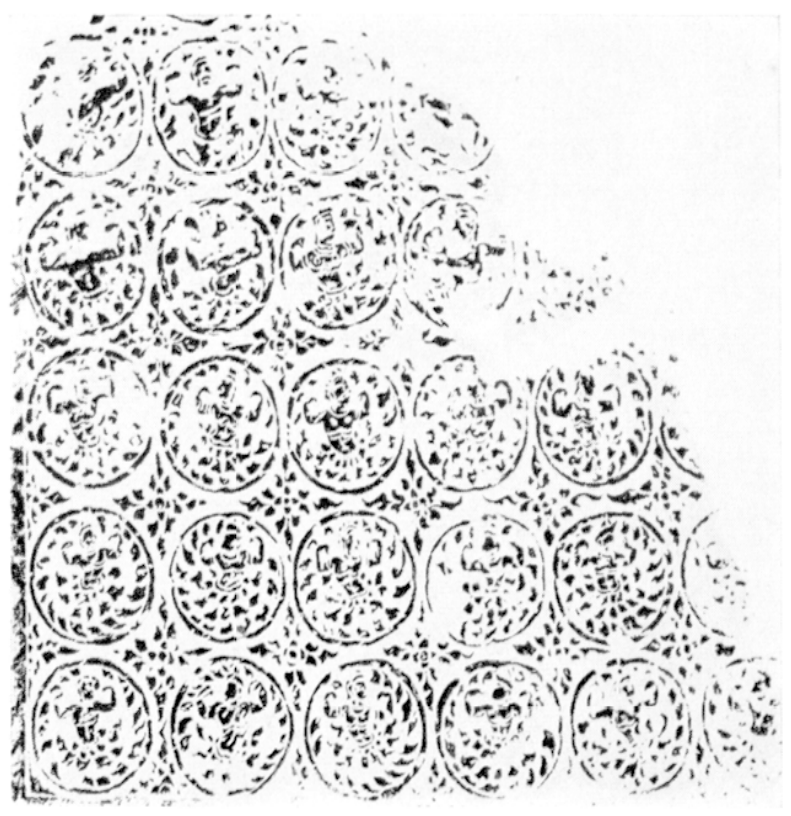

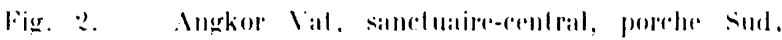

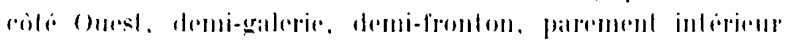

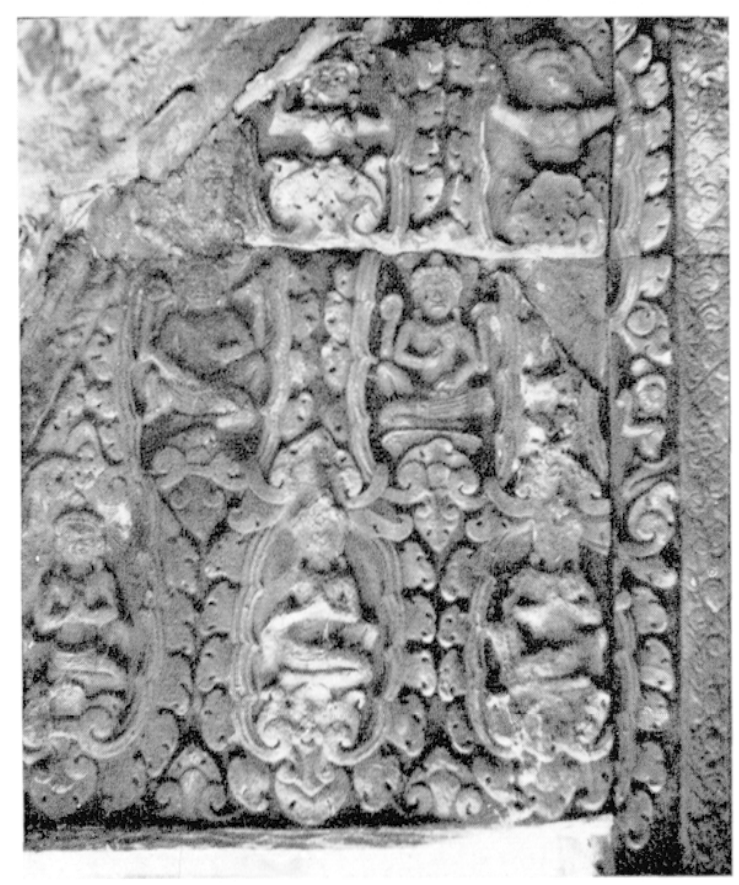

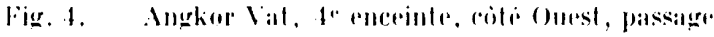
rharretier Nord, atle suld, demi-galerie, demi-fronton. parement exterieur. 
Hat 1)

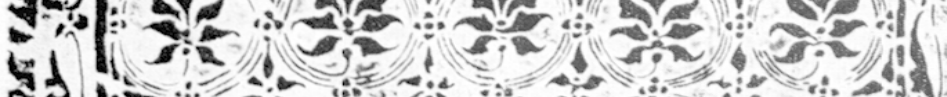

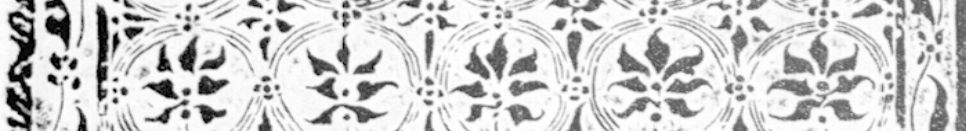

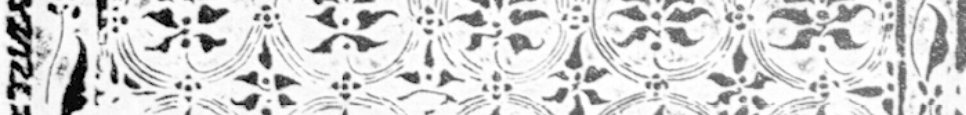
1.

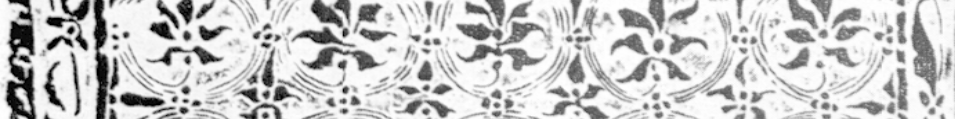

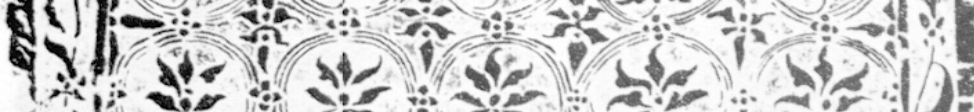

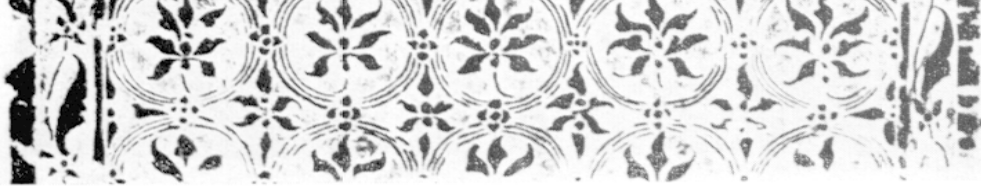

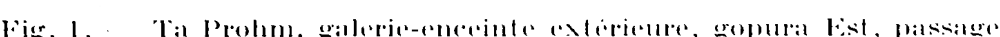
contral, alvint-corpes Nord, porte list, lithleitu Nond.
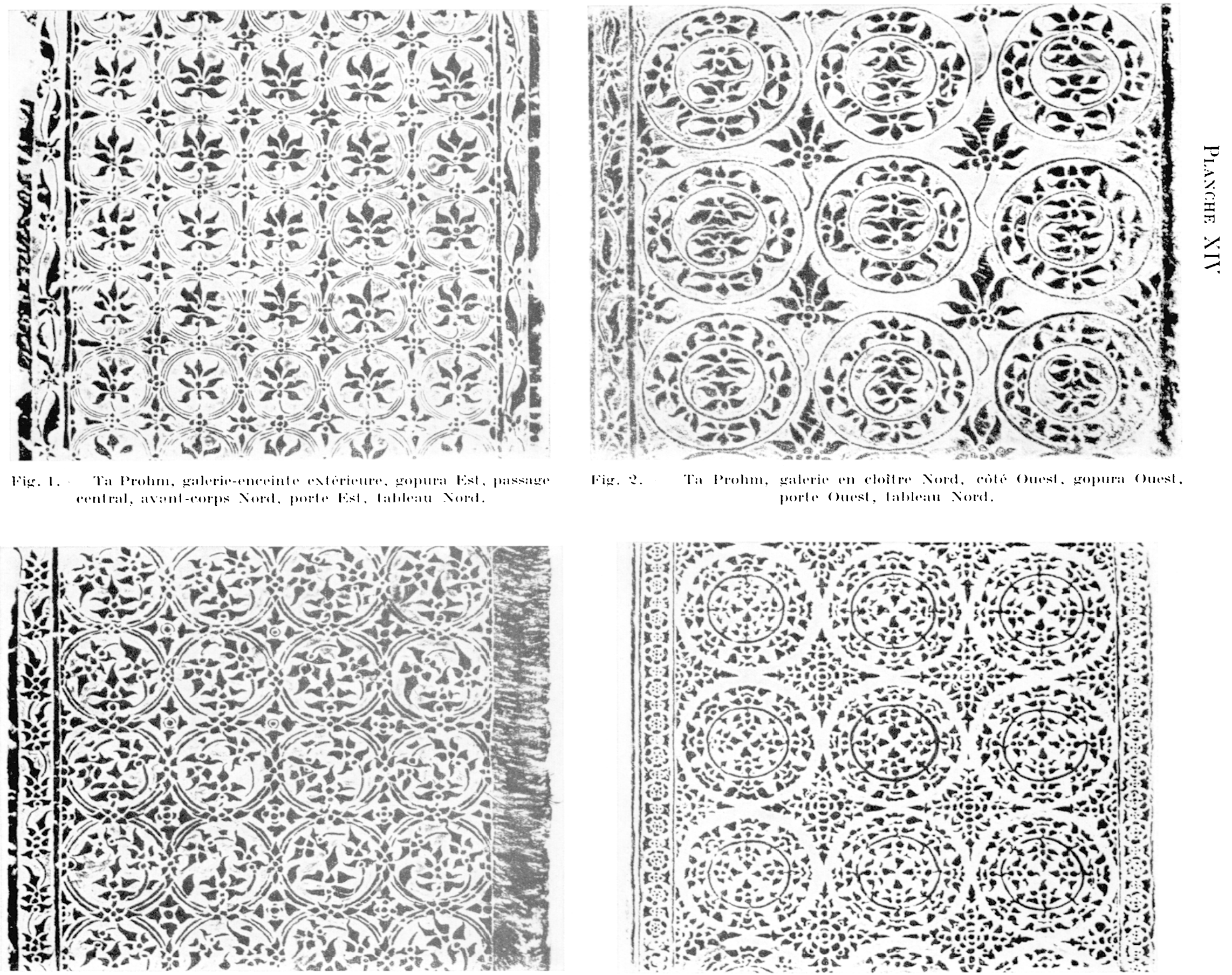

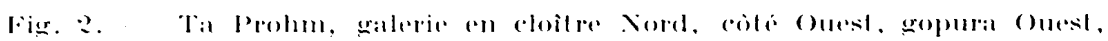

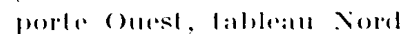

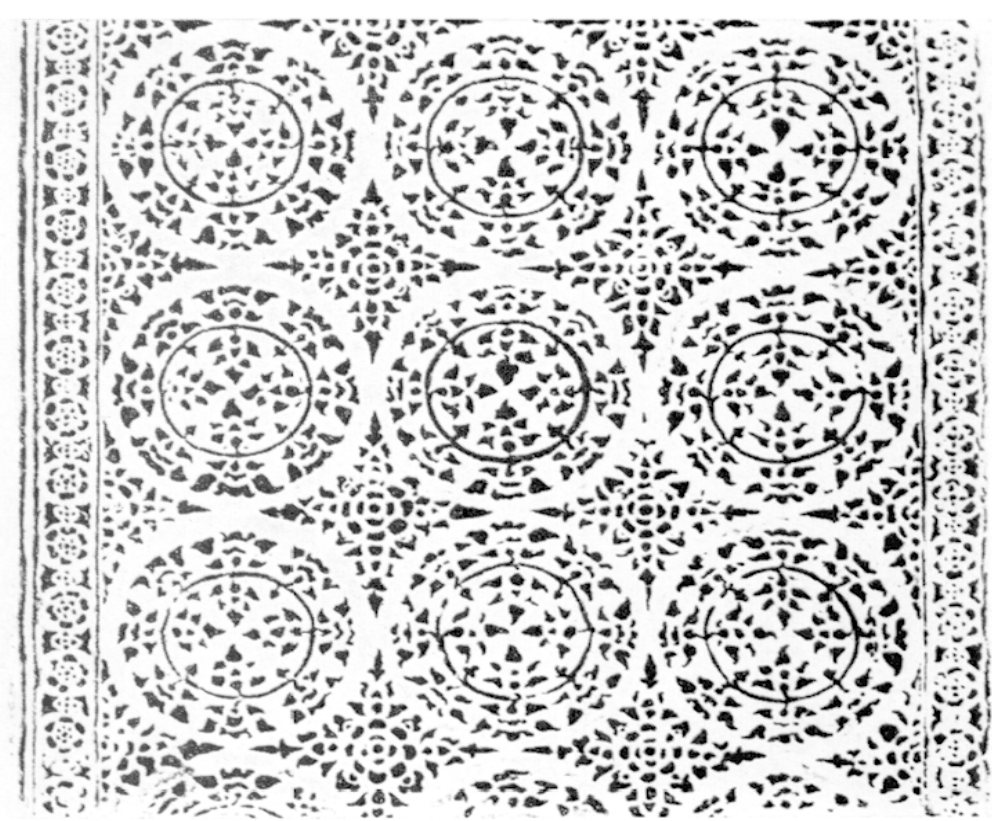




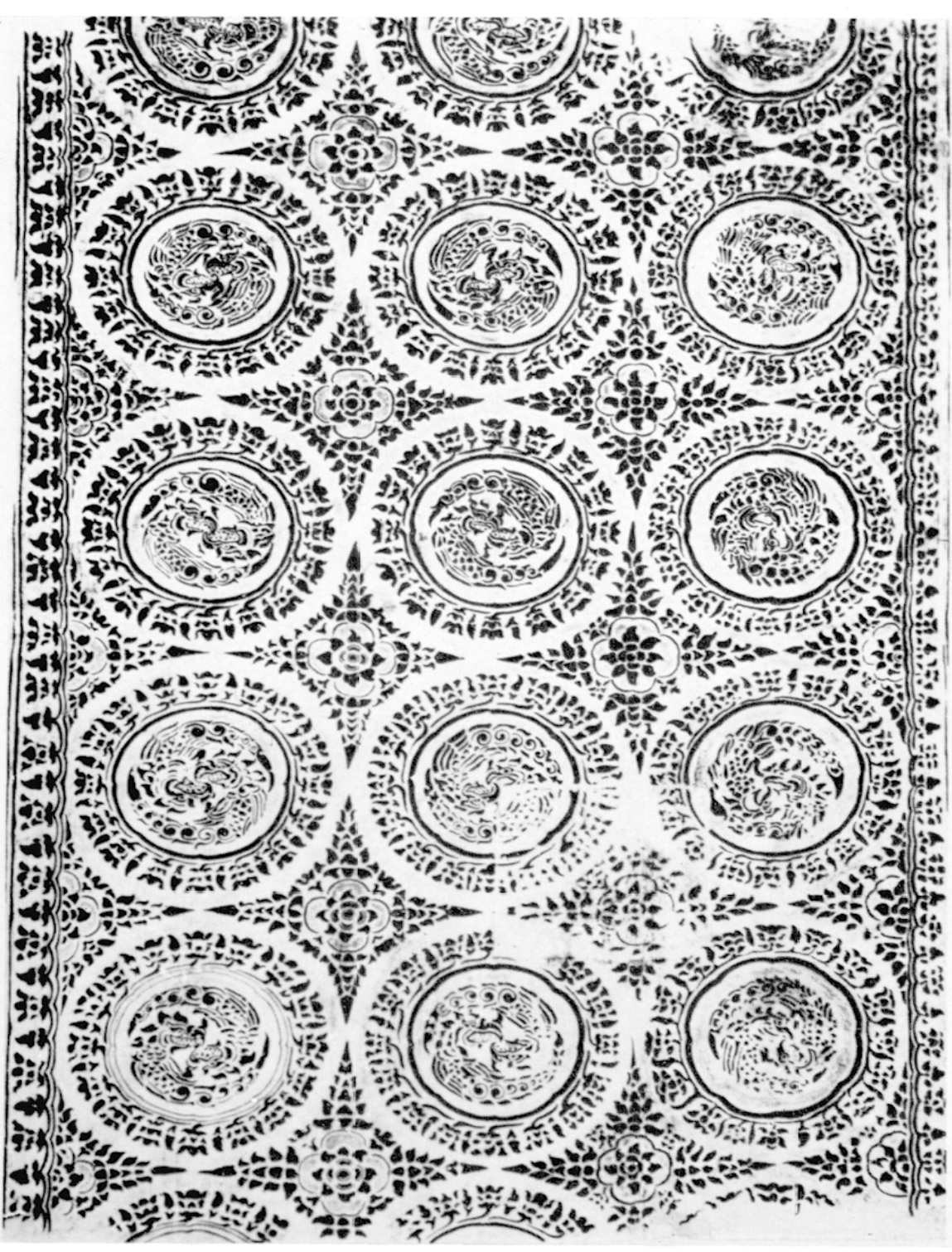

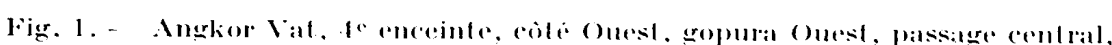
aile sud, fenetre Xord, tible:iu sud.

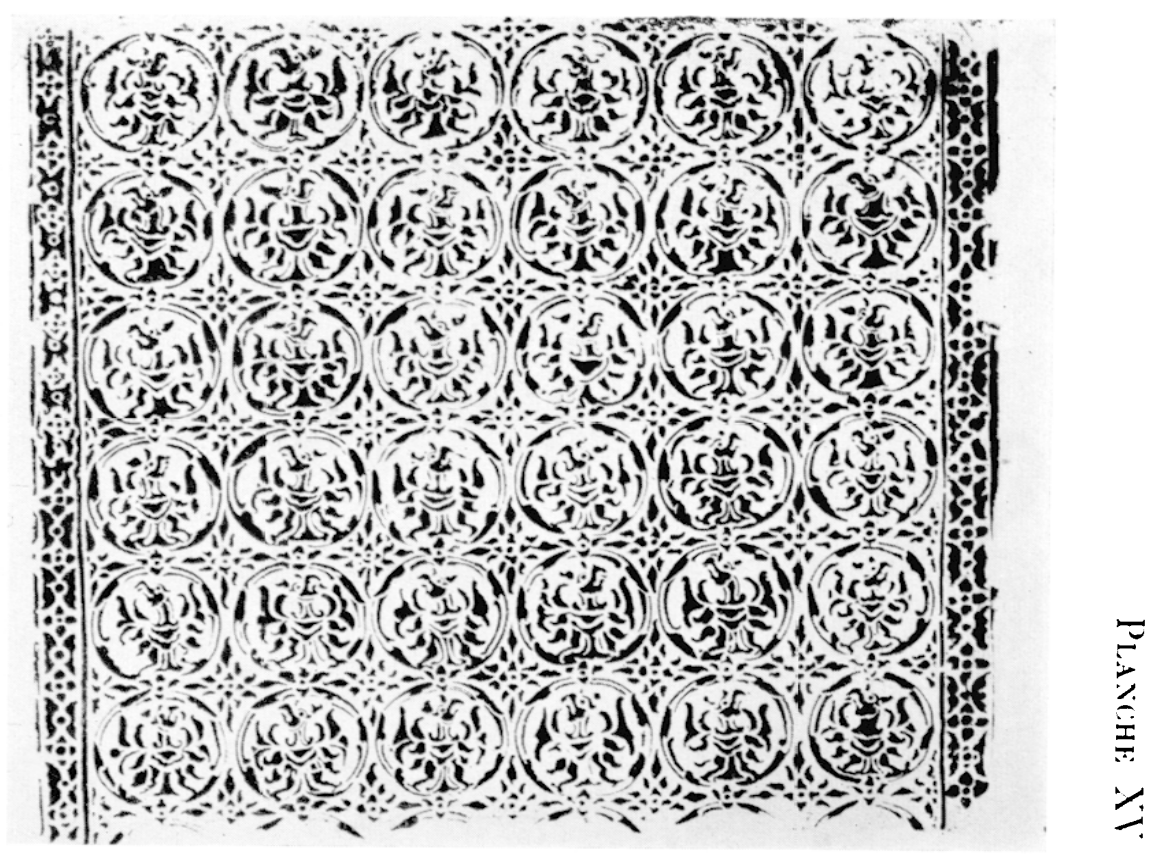

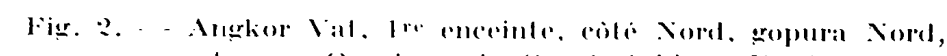

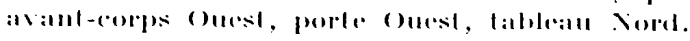




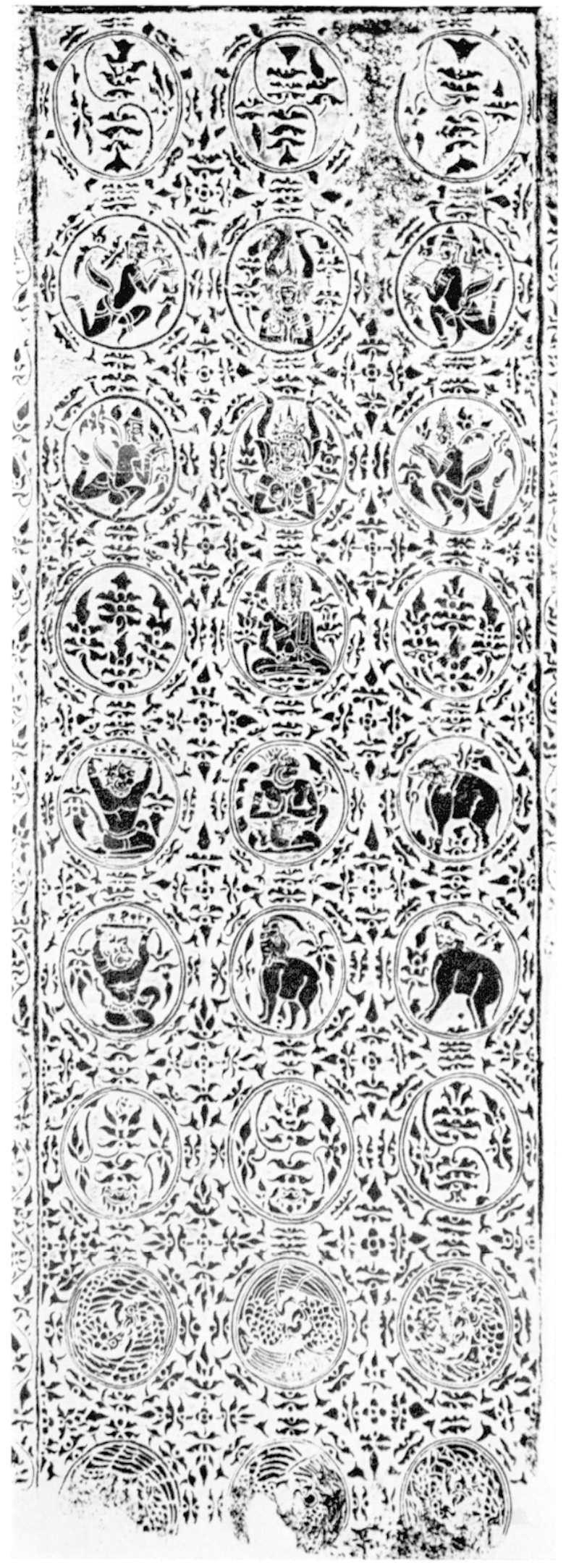

Figr. 1. ... Ta Jrohm, calerie-encrinte intrieure, cote Est, corps de galeric Sud, porte Est, lablean sud.

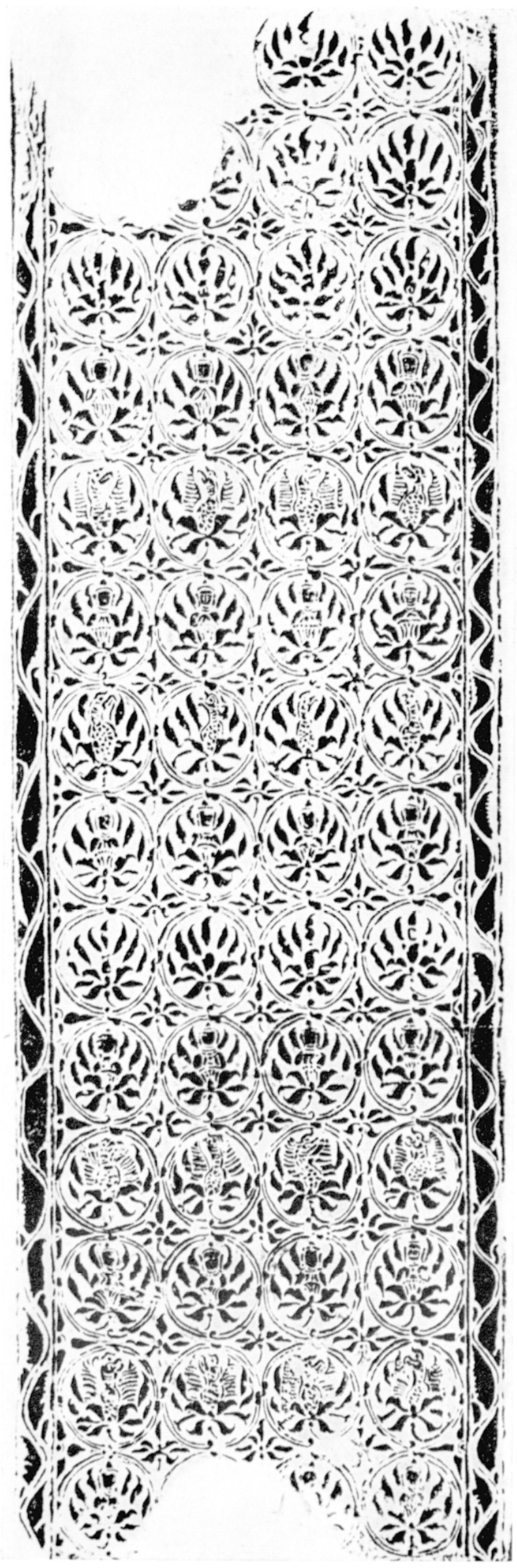

Figr. 2. -.. Ta Prohm, galerie-enceinte interieure, cote ouest, corps de galerie sud, porte lest, lableau sud. 